\title{
Predicting aquatic invasion in Adirondack lakes: a spatial analysis of lake and landscape characteristics
}

\author{
Richard R. Shaker, ${ }^{1,3} \dagger$ Artur D. Yakubov, ${ }^{2}$ StePhanie M. Nick, ${ }^{3}$ Erin Vennie-Vollrath, ${ }^{4}$ \\ Timothy J. EhLINGER, ${ }^{5}$ AND K. WAYNe Forsythe ${ }^{1}$ \\ ${ }^{1}$ Department of Geography E Environmental Studies, Graduate Programs in Environmental Applied Science E Management, \\ Ryerson University, Toronto, Ontario M5B 2K3 Canada \\ ${ }^{2}$ Department of Geography, Binghamton University, State University of New York, Binghamton, \\ New York 13902 USA \\ ${ }^{3}$ GeoEco Design, Syracuse, New York 13210 USA \\ ${ }^{4}$ Adirondack Park Invasive Plant Program, The Nature Conservancy-Adirondack Chapter, Keene Valley, New York 12943 USA \\ ${ }^{5}$ Partnership for Sustainability and Peacebuilding, Department of Biology, Center for Global Health Equity, \\ University of Wisconsin-Milwaukee, Milwaukee, Wisconsin 53211 USA
}

Citation: Shaker, R. R., A. D. Yakubov, S. M. Nick, E. Vennie-Vollrath, T. J. Ehlinger, and K. Wayne Forsythe. 2017. Predicting aquatic invasion in Adirondack lakes: a spatial analysis of lake and landscape characteristics. Ecosphere 8(3):e01723. 10.1002/ecs2.1723

\begin{abstract}
Invasive species continue to pose major challenges for managing coupled human-environmental systems. Predictive tools are essential to maximize invasion monitoring and conservation efforts in regions reliant on abundant freshwater resources to sustain economic welfare, social equity, and ecological services. Past studies have revealed biotic and abiotic heterogeneity, along with human activity, can account for much of the spatial variability of aquatic invaders; however, improvements remain. This study was created to (1) examine the distribution of aquatic invasive species richness (AISR) across 126 lakes in the Adirondack Region of New York; (2) develop and compare global and local models between lake and landscape characteristics and AISR; and (3) use geographically weighted regression (GWR) to evaluate non-stationarity of local relationships, and assess its use for prioritizing lakes at risk to invasion. The evaluation index, AISR, was calculated by summing the following potential aquatic invaders for each lake: Asian Clam (Corbicula fluminea), Brittle Naiad (Najas minor), Curly-leaf Pondweed (Potamogeton crispus), Eurasian Watermilfoil (Myriophyllum spicatum), European Frog-bit (Hydrocharis morsus-ranae), Fanwort (Cabomba caroliniana), Spiny Waterflea (Bythotrephes longimanus), Variable-leaf Milfoil (Myriophyllum heterophyllum), Water Chestnut (Trapa natans), Yellow Floating Heart (Nymphoides peltata), and Zebra Mussel (Dreissena polymorpha). The Getis-Ord Gi* statistic displayed significant spatial hot and cold spots of AISR across Adirondack lakes. Spearman's rank $(\rho)$ correlation coefficient test $\left(r_{\mathrm{s}}\right)$ revealed urban land cover composition, lake elevation, relative patch richness, and abundance of game fish were the strongest predictors of aquatic invasion. Five multiple regression global Poisson and GWR models were made, with GWR fitting AISR very well $\left(R^{2}=76-83 \%\right)$. Local pseudo-t-statistics of key explanatory variables were mapped and related to AISR, confirming the importance of GWR for understanding spatial relationships of invasion. The top 20 lakes at risk to future invasion were identified and ranked by summing the five GWR predictive estimates. The results inform that inexpensive and publicly accessible lake and landscape data, typically available from digital repositories within local environmental agencies, can be used to develop predictions of aquatic invasion with remarkable agreement. Ultimately, this transferable modeling approach can improve monitoring and management strategies for slowing the spread of invading species.
\end{abstract}

Key words: Adirondack Park Invasive Plant Program; alien-invasive species; applied ecology; geographically weighted regression; hot spot analysis; landscape configuration; landscape ecology; monitoring invasive species in lakes; Poisson regression; riparian zone; spatial ecology; species richness.

Received 12 December 2016; accepted 13 December 2016. Corresponding Editor: Debra P. C. Peters. 
Copyright: (C) 2017 Shaker et al. This is an open access article under the terms of the Creative Commons Attribution License, which permits use, distribution and reproduction in any medium, provided the original work is properly cited.

$\dagger$ E-mail: rshaker@ryerson.ca

\section{INTRODUCTION}

The integrity of the planet is being stressed beyond its limits (WWF 2015); thus, it is important to improve strategies and techniques for managing coupled human-environmental systems. Biodiversity is a key underlying indicator for evaluating environmental well-being associated with sustainability (Shaker 2015a), and at the global scale, it has steadily fallen over the last four decades (Butchart et al. 2010). Multiple interacting forces are linked to the decline of speciation, which have been summarized by conservation biologists and environmental managers under the acronym HIPPO: habitat destruction, invasive species, pollution, population, and overharvesting (Wilson 2002). Biodiversity loss is fueled largely by population growth, which has been recently projected to continue past 2100 (Gerland et al. 2014). The increased demand for socioeconomic well-being has metabolized natural landscapes, which is the most direct cause of ecosystem degradation (Vitousek et al. 1997, Foley et al. 2005, Liu et al. 2007, Shaker 2015b). Invasive species (IS), non-indigenous flora and fauna that adversely impact native ecosystems and economic activities that depend on them, is second only to habitat loss for decreasing biodiversity (Wilcove et al. 1998, Grime 2006). Over $40 \%$ of threatened or endangered species are considered at risk primarily due to alien-IS (Pimentel et al. 2005). That said, it is likely that freshwater ecosystems are the most impacted by anthropogenic-related stressors (Naiman and Turner 2000, Foley et al. 2005, MEA 2005, Novotny et al. 2005, Liu et al. 2007, Shaker and Ehlinger 2014).

Water resources management is considered a necessity for maintaining or improving human well-being (Baron et al. 2002, Gleick 2003). To support this, many world nations have adopted laws at different levels of government to protect or improve the integrity of hydrologic systems (Karr 2006). In the United States, the Clean Water Act (1972) has a goal of restoring and maintaining the chemical, physical, and biological integrity of the Nation's waters. The Act also defined pollution as any human activity that degrades a water body's integrity. Specifically, "integrity" is defined as the ability of a landscape-aquatic ecosystem to support and maintain "a balanced integrated, adaptive community of organisms having a species composition, diversity, and functional organisms comparable to that of a natural biota of the region" (Karr et al. 1986). In many world regions, human activities have altered landscapes, and their associated aquatic ecosystems, such that restoring them to any predisturbed form is likely impossible (Novotny 2003). Major anthropogenic causes include land cover modification that changes natural hydrology, non-point and point discharge of pollutants from various sources, and the introduction of non-indigenous flora and fauna that adversely impact the integrity of native ecosystems.

The negative impacts of IS on native species, communities, and ecosystems have been widely investigated since the late 1950s (Lodge 1993, Simberloff 1996, Elton 2000), and are now considered a substantial component of global environmental change (Vitousek et al. 1996). Aquatic and terrestrial IS can completely disrupt the function of ecosystems, replace native species, and destroy human-oriented constructions such as fisheries (Simberloff et al. 2005). The severe economic impact of these species is unmistakable; estimated costs of invasives worldwide total more than \$1.4 trillion- $5 \%$ of the global economy (Pimentel et al. 2001). Economic damages and control costs due to IS are valued at $\$ 120$ billion annually in the United States alone (Pimentel et al. 2005).

In an example specific to aquatic invasion, maintenance costs for electricity generation and water treatment facilities due to Zebra Mussels (Dreissena polymorpha) were estimated at \$267 million in North America, from 1989 to 2004 (Connelly et al. 2007). Additionally, Zhang and Boyle (2010) found that the presence of Eurasian Watermilfoil (Myriophyllum spicatum) in lakes could decrease surrounding property values by more than $15 \%$. An assessed $\$ 500$ million in economic losses occur each year in the Hudson River system and New York State Canals from 
some 154 non-native species; $80 \%$ of that loss is in commercial and sport fishing (APA 2015). To mitigate impacts associated with IS, the U.S. government created Executive Order no. 13112 to direct federal agencies "to prevent the introduction of IS and provide for their control and to minimize the economic, ecological, and human health impacts that IS cause" (EO 1999:6183-6186). To further decrease IS impacts, local environmental agencies continue to create new planning and policy initiatives. In example, the New York State Department of Environmental Conservation enacted efforts in 2015 to slow the spread of IS by establishing the state's first lists of prohibited and regulated species (6 NYCRR § 575). Despite a growth of environmental management initiatives, IS continue to pose major challenges worldwide. Specific to the forthcoming study, the Adirondack Park Agency (APA) has seen a steady increase in the establishment of harmful exotic species since monitoring began in 2001 (APIPP 2013). Using publicly available databases, this study was created to (1) identify important lake and landscape conditions that predict aquatic invasive species richness (AISR) and (2) improve IS monitoring tools for progressing detection and management efforts.

\section{Lake and landscape approach}

Humans are the main propagators of IS, and globalization has exacerbated that rate of invasion. Invasion is a multi-step process comprising the following three phases: (1) initial dispersal (where an organism moves from its native habitat, often over long distances, to a new habitat outside of its home range); (2) establishment of self-sustaining populations within the new habitat; and (3) spread of the organism to nearby habitats (Puth and Post 2005). Once established, IS are often impossible to eradicate. The initial dispersal stage of invasion is the phase that the other two rest; thus, it is during this stage that efforts can prevent the establishment and subsequent impacts of IS (Simberloff et al. 2005). Therefore, it may be possible to slow harmful non-indigenous species, prioritize management resources, and protect environmentally sensitive areas, by predicting where invaders are most likely to spread (Buchan and Padilla 2000). Predictive tools are essential to maximize IS monitoring and conservation efforts in regions reliant on abundant freshwater resources to sustain economic welfare, social equity, and ecological services.

The development of appropriate management strategies to protect freshwater resources and services from aquatic invasive species (AIS) requires a thorough understanding of coupled human-environmental systems that support their initial dispersal, establishment of a selfsustaining population, and spread (Puth and Post 2005). The means and routes that IS are introduced into new environments are called "vectors" and "pathways," respectively. Much of AIS transmission has been linked to the overland movement of small-craft boats (e.g., Leung et al. 2006, Rothlisberger et al. 2010). Small-craft boats are vessels less than 40 feet $(12.2 \mathrm{~m})$ in length, including canoes and kayaks, personal watercrafts, powerboats, small commercial and recreational fishing boats, sailboats, and pontoon boats, and associated fishing gear, that can be towed overland on trailers (Rothlisberger et al. 2010). Other relevant lake and landscape predictors of aquatic invasion include lake area, elevation, surrounding land cover composition, and landscape diversity measures (Shaker et al. 2013); factors that influence water quality, number of game fish, number and type of boat ramps, bedrock type, littoral area, water source, number of residences, and proximity to roads (Buchan and Padilla 2000); distance to nearest invaded waterway, lake size, alkalinity, Secchi depth, and lake depth (Roley and Newman 2008); riparian use, interaction with other IS, substrate material, and debris (Maezo et al. 2010); wave action, water-level drawdown, photic zone depth, aquatic vegetation shading, and native species present (Olson et al. 2012). Lastly, global environmental fluctuations linked to climate change are projected to accelerate the stages of invasion and ultimately exacerbate their spread (Hellmann et al. 2008, Rahel and Olden 2008).

Future societal and natural unknowns make it difficult to accurately predict outcomes for coupled human-environmental systems. The existing challenges associated with global environmental change, and the agreed upon remedy of sustainable development, are dependent on applied research (Shaker 2015a). Since it is impossible to measure all water parameters associated with predicting aquatic invasion, a landscape ecology approach allowed for landscape proxies during 
predictive modeling. Landscape ecology is a multidisciplinary science for understanding relationships between ecological processes and geographic patterns across spatial and temporal scales (Wu and Hobbs 2007). Because landscapes are inherently interconnected geophysical, biological, and socioeconomic systems, this modeling approach was deemed suitable for this study. Evaluation indices can be used to calibrate, or gauge, a landscape using a single number, and have been used widespread in landscape-aquatic ecological studies (i.e., Alberti et al. 2007, Shandas and Alberti 2009, Shaker and Ehlinger 2014). Monitoring, modeling, and assessing coupled landscape-aquatic ecosystems can be accomplished using landscape ecology tools and spatial analysis methods (i.e., Shaker et al. 2010, Shaker and Ehlinger 2014). Previously, studies have illustrated the importance of including configuration metrics into landscape-aquatic condition research (e.g., Alberti et al. 2007, Shandas and Alberti 2009, Shaker and Ehlinger 2014); however, few have directly investigated how riparian landscape patterns influence the dispersal, survival, or propagation of harmful exotic species.

Monitoring IS across large geographic extents remains one of the greatest challenges to slowing their advancement. This research builds upon previous studies (i.e., Buchan and Padilla 2000, Capers et al. 2009) to further investigate relationships between lake and landscape characteristics and AIS. Biotic and abiotic heterogeneity of lake and landscape conditions along with human activity can account for much of the spatial variability of aquatic invaders; however, important research remains. This study was organized around three guiding objectives to (1) examine the distribution of AISR across 126 lakes in the Adirondack Region of New York; (2) develop and compare global and local models between lake and landscape characteristics and AISR; and (3) use geographically weighted regression (GWR) to evaluate non-stationarity of local relationships, and assess its use for prioritizing lakes at risk to invasion. This research aimed to improve scientific and applied understanding of coupled landscape-aquatic ecological relationships. It also serves to provide environmental management agencies', scientists', environmental planners', and policymakers' macroscale techniques for monitoring and modeling IS.

\section{Study area}

The Adirondack Park is the premier state-level park in the northeastern United States, with a longstanding history of preservation, conservation, and public-private partnership. It is an Upstate New York protected area and National Historic Landmark. New York Legislation established the basis of the Park around forest preservation in 1885, but it was not until 1892 that the Park was officially created. Environmental stewardship of the Adirondacks was furthered with the "forever wild" amendment to the state constitution in 1894. Through Article 14 of the New York State Constitution, the Forest Preserve lands are constitutionally protected: "The lands now or hereafter constituting them shall be forever kept as wild forest lands. They shall not be sold, nor shall they be leased or taken by any person or corporation public or private." Later, the New York State Legislature created the APA in 1971 with the mission to protect private and public resources within Park limits (commonly known as the "Blue Line") through the exercise of the powers and duties of the Agency as provided by law (APA 2015). The thesis of the APA Act is "to ensure optimum overall conservation, development, and use of the unique scenic, aesthetic, wildlife, recreational, open space, historic, ecological, and natural resources of the Adirondack Park." In response to protecting the Adirondack Region from the negative impacts of invading species, the APA, The Nature Conservancy, New York Department of Environmental Conservation (NYDEC), and Department of Transportation (DOT) initiated the Adirondack Park Invasive Plant Program (APIPP) in 1998. The Adirondack Chapter of The Nature Conservancy houses APIPP. APIPP coordinates two regional projects: the Aquatic Invasive Species Project and the Terrestrial Invasive Species Project.

The Adirondack Park is the largest state-level park in the conterminous United States and is comparable in size to the State of Vermont. The Adirondack Park region of New York covers 2.4 million hectares (5.9 million acres) and includes roughly 103,000 ha (398 miles ${ }^{2}$ ) of lakes and $13,000 \mathrm{~km}$ (8078 miles) of streams (Regalado and Kelting 2015). The Park boundary overlaps with five major watersheds, and roughly half of its landscapes drain into the Laurentian Great 
Lakes. Twelve counties intersect the Park limits, with only Essex and Hamilton Counties wholly within its borders. Within the "Blue Line" limits of the Park, a wide variety of habitats including wetlands and old-growth forests exist, significant topographic variation with 46 high mountain peaks (max elevation $=1629 \mathrm{~m} ; 5343 \mathrm{ft}$.) which draw many outdoor enthusiasts. Situated within a day's drive of New York City and Montreal, the Park is well positioned to offer its unique blend of wilderness solitude, outdoor recreation, and community life to millions of visitors who, in increasing numbers, view the Park as a unique travel destination. According to Sharpe et al. (2001), over 200,000 seasonal residents and six million visitors are attracted to the Park annually. Furthermore, the Park is home to 132,000 permanent residences and has over 100 towns and villages (APA 2015). The mixture of public and private lands is a distinguishing feature of the Park. As of 2013, state owned land, private owned land, and water features account for $51 \%$, $43 \%$, and $6 \%$ of total Park area, respectively (APSLMP 2014). Lastly, the Park contains over $8000 \mathrm{~km}$ of paved roads, grouped into $1965 \mathrm{~km}$ of state and federal roads, $1803 \mathrm{~km}$ of county roads, and $4421 \mathrm{~km}$ of local roads (Regalado and Kelting 2015).

A total of 126 lakes, selected with areas greater than 25 hectares to assure data accuracy, were provided from the APIPP (2013) Annual Report (Fig. 1). At that time, 94 lakes recorded at least one aquatic invasive plant or animal from the total 311 waterways surveyed (APIPP 2013). The 126 lakes cross all 12 counties of the Park, which include a vast diversity of lake (i.e., area) and landscape (i.e., elevation) conditions. The water resources of the region are critical for maintaining the environmental and socioeconomic well-being of the Park. The water's designated use, established by the state, also impacts bordering land holdings and use. Major causes of aquatic impairment within the Adirondack Park are linked to poor land-use practices, acidification of waters through regional deposition, and the spread of AIS. First documented in 1984 by the Adirondack Biota Project, $54 \%$ of the region's lakes have a $\mathrm{pH}$ below 5.5 (Nierzwicki-Bauer et al. 2010). Additionally, the Park receives levels of nitrate $\left(\mathrm{NO}_{3}{ }^{-}\right)$ and ammonium $\left(\mathrm{NH}_{4}^{+}\right)$deposition that are among the highest in the northeastern United
States (McNeil et al. 2006). Although the Acid Deposition Control Program of the Clean Air Act Amendments (1990) has significantly reduced acidic deposition (Driscoll et al. 2001), and the land-water interface increasingly receives management attention, it can be presumed population growth and increased tourism will intensify AIS propagation. To end, it is likely that the greatest threat to Park biodiversity comes from the ecosystem dangers associated with IS.

\section{Materials and Methods}

\section{Aquatic invasive species richness}

Monitoring programs for evaluating human impacts on water resources have existed for decades, with a variety of measuring techniques being applied to aquatic organisms as indicators of biological integrity. Specifically, indicators of aquatic integrity (i.e., Index of Biotic Integrity) are commonplace for measuring impacts of human activities and are used on six of the seven continents throughout the world (Roset et al. 2007). Biological indices are considered robust tools for investigating landscape-aquatic interactions (Karr and Yoder 2004, Novotny et al. 2005), and they can help diagnose causes of ecological impacts and suggest appropriate management actions (Karr and Chu 1999). These response indices, or biotic assessment endpoints, provide the ecological status (integrity) of the water body because the biota captures the compounding stress found within the interconnected ecosystem (Novotny et al. 2005). Building on previous aquatic invasion studies (i.e., Capers et al. 2007, 2009), this research uses a fundamental biotic endpoint, AISR, as an evaluation index of lake and landscape characteristics. AISR was calculated by summing the number of invasive plants or animals recorded present within each of the 126 lakes from the APIPP (2013) Annual Report.

Eleven aquatic invaders have continually been monitored across the Adirondack Park since 2001. The 11 AIS monitored are Asian Clam (Corbicula fluminea), Brittle Naiad (Najas minor), Curly-leaf Pondweed (Potamogeton crispus), Eurasian Watermilfoil (Myriophyllum spicatum), European Frogbit (Hydrocharis morsus-ranae), Fanwort (Cabomba caroliniana), Spiny Waterflea (Bythotrephes longimanus), Variable-leaf Milfoil (Myriophyllum heterophyllum), Water Chestnut (Trapa natans), Yellow 


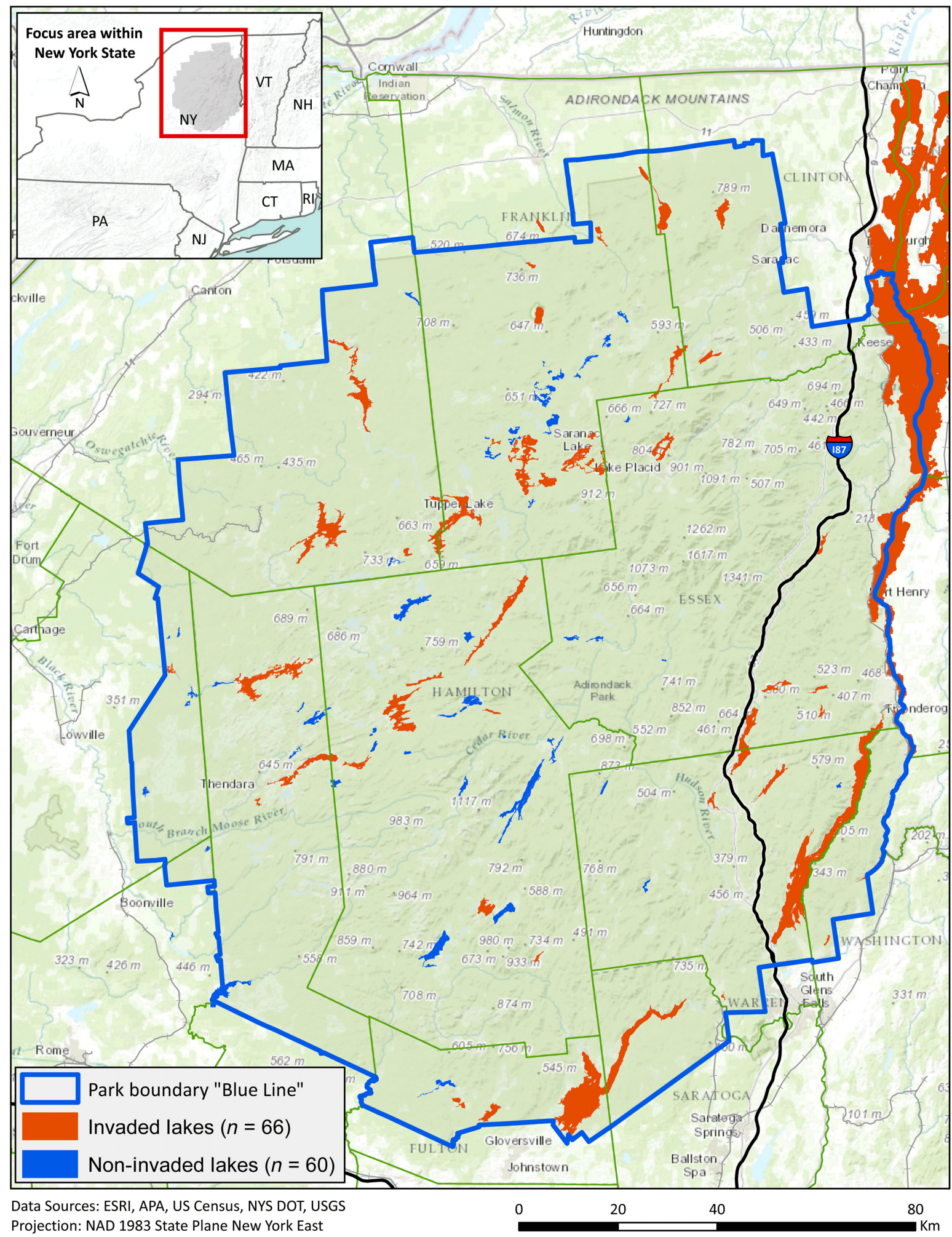

Fig. 1. Study area map of 126 lakes within the Adirondack Park region of New York, United States $\left(43^{\circ} 56^{\prime} \mathrm{N}\right.$, $\left.74^{\circ} 23^{\prime} \mathrm{W}\right)$. 


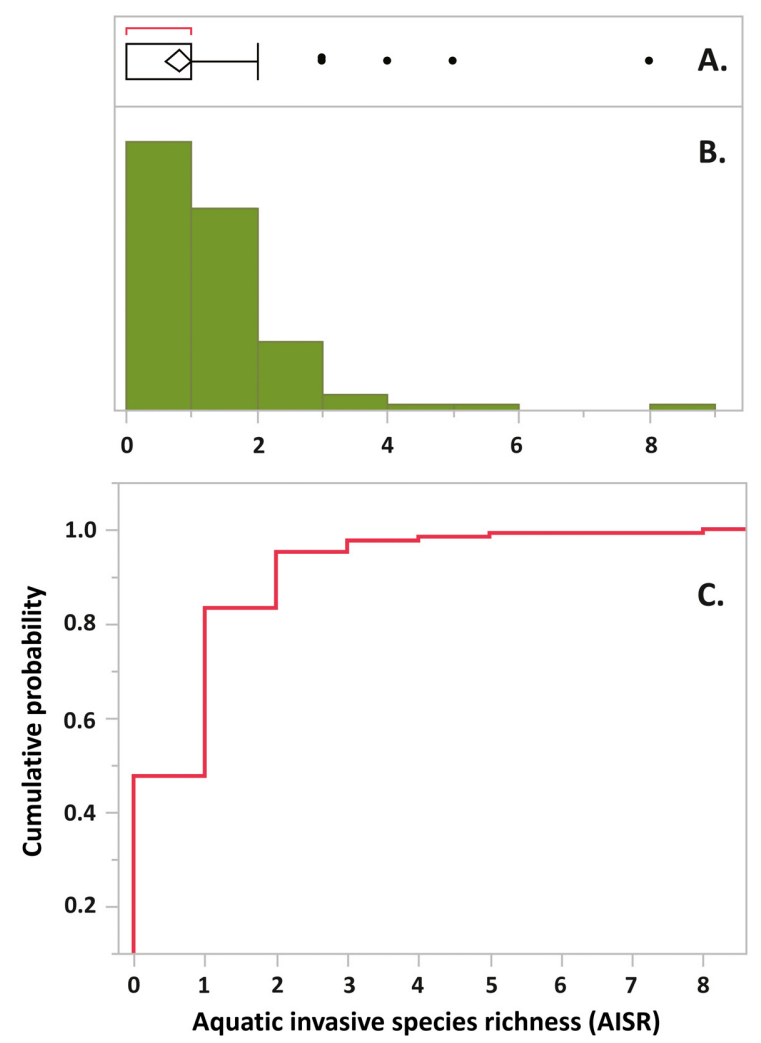

Fig. 2. Poisson distribution of aquatic invasive species richness identified in lakes according to the Adirondack Park Invasive Plant Program (APIPP 2013) annual report: box plot displaying quartiles and confidence diamond for mean value (A), frequency histogram (B), and cumulative probability graph (C).

Floating Heart (Nymphoides peltata), and Zebra Mussel (Dreissena polymorpha). Of the total sample size lakes $(N=126)$, IS occurred in 66 of them; of lakes with invasives, 45 had a single species, 15 had two, three had three, one had four, one had five, and one had eight (Fig. 2). As of the 2013 report date, the only lake registering eight aquatic invaders was Lake Champlain. AISR ranged from 0 to 8 species (mean $\pm \mathrm{SE}=0.80 \pm 0.10$ ) across the 126 Adirondack lakes and followed a classic Poisson distribution.

\section{Lake and landscape characteristics}

To develop and test predictive models, lake and landscape information was compiled or created from publicly accessible datasets (Data S1). Thirtyone lake and landscape measures were obtained directly, or through GIS processing of spatial databases, from the APIPP, U.S. Census, DOT, NYDEC, Sportsman's Connection Fishing Guide (SCFG), and the U.S. Geological Survey (USGS; Table 1). Due to macroscale management and database limitations across the study area lakes, direct measures of chemical, geological, and biological parameters could not be included during model development. That said, it is commonly understood that measures of lake, landscape, and land cover can serve as proxies because they are inherently collinear with soils, sub-surface geology, surface hydrology, aspects of groundwater hydrology, and lake chemistry (see Wagner and Fortin 2005, Dale and Fortin 2014, Turner and Gardner 2015). Therefore, this research takes a landscape ecology and macroscale spatial analysis approach to fulfill its three guiding aquatic invasive research objectives. For organizational purposes, variables gathered and calculated can be grouped as follows: (1) those that are impacting human access or physical geography of the lake and (2) landscape calculated variables of land cover composition, configuration, and diversity. Herein, these two broad groupings of modeling variables are referenced as (1) lake characteristics and (2) landscape characteristics.

Lake characteristics classified as continuous measures for predicting AISR were lake area, perimeter, perimeter/area ratio, maximum depth, surface elevation, and Euclidean distance to nearest invaded lake. Lake depth came from the most current SCFG, while lake elevation was calculated using a $10-\mathrm{m}$ resolution digital elevation model provided by the USGS. Ordinal variables were lake access type and game fish abundance. Lake access type was coded carry down only or public launch. The abundance of game fish represents if yellow perch, smallmouth bass, and rainbow trout were found in the lake. These data were ordinally summed to create game fish species richness, and ranged from absent to all three species present (0-3). Landscape characteristics were quantified from the 2011 National Land Cover Database (NLCD) for New York, which was released in the spring of 2014 for the state. The 2011 NLCD is a seamless Landsat Thematic Mapper database preserving $30-\mathrm{m}$ raster resolution of vegetation type, and was designed for an array of topics such as assessing ecosystem status and integrity, understanding spatial patterns of habitat-biodiversity relationships, interpreting climate change, developing land 
Table 1. Lake and landscape data included in forthcoming statistical analyses (data are not transformed; $N=126)$.

\begin{tabular}{|c|c|c|c|c|c|c|}
\hline \multirow[b]{2}{*}{ Variable } & \multirow[b]{2}{*}{ Units/information } & \multirow[b]{2}{*}{ Source } & \multirow[b]{2}{*}{ Classification } & \multirow[b]{2}{*}{ Min-max } & \multicolumn{2}{|c|}{$\begin{array}{l}\text { Mean } \pm \text { SE, percentage of } \\
\text { lakes and landscapes }\end{array}$} \\
\hline & & & & & Invaded & Non-invaded \\
\hline AISR & $\begin{array}{l}\text { Sum of species } \\
\text { present }\end{array}$ & APIPP & Ordinal & $0-8$ & $52 \%$ & $48 \%$ \\
\hline Lake area & $\mathrm{km}^{2}$ & NYDEC & Continuous & $0.2-1122.5$ & $24.9 \pm 17.0$ & $2.1 \pm 0.4$ \\
\hline Lake perimeter & $\mathrm{km}$ & NYDEC & Continuous & 1.9-1037.4 & $45.0 \pm 16.2$ & $13.4 \pm 1.8$ \\
\hline Lake perimeter/area ratio & $\mathrm{km} / \mathrm{km}^{2}$ & NYDEC & Continuous & $0.9-19.9$ & $6.9 \pm 0.5$ & $9.3 \pm 0.5$ \\
\hline Maximum depth & $\mathrm{m}$ & $\begin{array}{l}\text { NYDEC, } \\
\text { SCFG }\end{array}$ & Continuous & $1.5-402.9$ & $21.0 \pm 6.0$ & $14.9 \pm 1.1$ \\
\hline Lake surface elevation & $\mathrm{m}$ & USGS & Continuous & $28.9-651.7$ & $415.8 \pm 15.4$ & $496.0 \pm 7.0$ \\
\hline Lake access type & $\begin{array}{l}\text { 1) Carry down only } \\
\text { 2) Public launch km }\end{array}$ & SCFG & Ordinal & 1,2 & $\begin{array}{l}24.2 \% \\
75.8 \%\end{array}$ & $\begin{array}{l}55 \% \\
45 \%\end{array}$ \\
\hline $\begin{array}{l}\text { Distance to nearest invaded } \\
\text { lake }\end{array}$ & $\mathrm{km}$ & APIPP & Continuous & $1.2-32.1$ & $6.8 \pm 0.6$ & $10.4 \pm 0.8$ \\
\hline $\begin{array}{l}\text { Game fish abundance: yellow } \\
\text { perch, smallmouth bass, } \\
\text { rainbow trout }\end{array}$ & $\begin{array}{l}\text { 0) Absent } \\
\text { 1) One species } \\
\text { 2) Two species } \\
\text { 3) Three species }\end{array}$ & SCFG & Ordinal & $0-3$ & $\begin{array}{c}1.5 \% \\
33.3 \% \\
34.8 \% \\
30.4 \%\end{array}$ & $\begin{array}{c}16.7 \% \\
45.0 \% \\
31.7 \% \\
6.6 \%\end{array}$ \\
\hline Distance to I-87 exit & $\mathrm{km}$ & DOT & Continuous & $2.6-116.8$ & $54.7 \pm 3.4$ & $64.4 \pm 3.2$ \\
\hline $\begin{array}{l}\text { Distance to nearest populated } \\
\text { place }\end{array}$ & $\mathrm{km}$ & CENSUS & Continuous & $0.2-13.6$ & $3.6 \pm 0.2$ & $3.2 \pm 0.3$ \\
\hline Land cover composition $\dagger$ & $\begin{array}{l}\text { Percentage of total } \\
\text { landscape area }\end{array}$ & USGS & Continuous & & & \\
\hline Developed, open space (DO) & $\%$ & & & $0-26.0 \%$ & $4.3 \% \pm 0.6 \%$ & $2.5 \% \pm 0.3 \%$ \\
\hline Developed, low intensity & $\%$ & & & $0-6.9 \%$ & $0.7 \% \pm 0.2 \%$ & $0.2 \% \pm 0.1 \%$ \\
\hline Developed, medium intensity & $\%$ & & & $0-4.4 \%$ & $0.4 \% \pm 0.1 \%$ & $0.1 \% \pm 0.02 \%$ \\
\hline Deciduous forest & $\%$ & & & $0-60.6 \%$ & $19.9 \% \pm 1.6 \%$ & $25.1 \% \pm 1.7 \%$ \\
\hline Evergreen forest (EF) & $\%$ & & & $1.2-60.6 \%$ & $17.4 \% \pm 1.4 \%$ & $23.0 \% \pm 1.7 \%$ \\
\hline Mixed forest & $\%$ & & & $0-32.9 \%$ & $5.9 \% \pm 0.8 \%$ & $4.7 \% \pm 0.4 \%$ \\
\hline Pasture/hay & $\%$ & & & $0-3.5 \%$ & $0.1 \% \pm 0.1 \%$ & $0.1 \% \pm 0.1 \%$ \\
\hline Cultivated crops & $\%$ & & & $0-1.1 \%$ & $0.1 \% \pm 0.03 \%$ & $0.01 \% \pm 0.01 \%$ \\
\hline Woody wetlands & $\%$ & & & $0-25.3 \%$ & $3.4 \% \pm 0.5 \%$ & $3.6 \% \pm 0.6 \%$ \\
\hline $\begin{array}{l}\text { Emergent herbaceous } \\
\text { wetlands }\end{array}$ & $\%$ & & & $0-14.3 \%$ & $0.7 \% \pm 0.2 \%$ & $0.9 \% \pm 0.3 \%$ \\
\hline $\begin{array}{l}\text { Land cover class } \\
\text { configuration } \dagger\end{array}$ & & USGS & Continuous & & & \\
\hline AI, DO & $\%$ & & & $0-86.7 \%$ & $52.7 \% \pm 2.4 \%$ & $41.8 \% \pm 3.5 \%$ \\
\hline AI, EF & $\%$ & & & $54.1-90.9 \%$ & $75.2 \% \pm 0.7 \%$ & $76.8 \% \pm 0.9 \%$ \\
\hline PLADJ, DO & $\%$ & & & $0-81.2 \%$ & $48.3 \% \pm 2.3 \%$ & $36.7 \% \pm 3.2 \%$ \\
\hline PLADJ, EF & $\%$ & & & $48.5-88.5 \%$ & $72.7 \% \pm 0.8 \%$ & $73.7 \% \pm 1.0 \%$ \\
\hline AREA_AM, DO & $\mathrm{m}^{2}$ & & & $0-55.83$ & $6.6 \pm 0.9$ & $4.2 \pm 1.1$ \\
\hline AREA_AM, EF & $\mathrm{m}^{2}$ & & & $0.96-135.01$ & $25.4 \pm 3.2$ & $24.5 \pm 3.3$ \\
\hline ENN_AM, DO & $\mathrm{m}$ & & & $0-5480.8$ & $198.4 \pm 82.7$ & $85.8 \pm 12.6$ \\
\hline ENN_AM, EF & $\mathrm{m}$ & & & $13.5-456.1$ & $108.6 \pm 7.7$ & $113.8 \pm 8.5$ \\
\hline Landscape diversity $\dagger$ & & USGS & Continuous & & & \\
\hline RPR & $\%$ & & & $25-93.8 \%$ & $62.2 \% \pm 1.8 \%$ & $51.4 \% \pm 1.7 \%$ \\
\hline SHDI & $\begin{array}{l}\text { SHDI } \geq 0, \\
\quad \text { without limit }\end{array}$ & & & $0.81-2.01$ & $1.40 \pm 0.03$ & $1.41 \pm 0.03$ \\
\hline SHEI & $0 \leq \mathrm{SHEI} \leq 1$ & & & $0.29-0.94$ & $0.62 \pm 0.01$ & $0.69 \pm 0.01$ \\
\hline
\end{tabular}

Notes: AISR, Aquatic invasive species richness; APIPP, Adirondack Park Invasive Plant Program; CENSUS, U.S. Census; DOT, Department of Transportation; NYDEC, New York State Department of Environmental Conservation; SCFG, Sportsman's Connection Fishing Guide; USGS, U.S. Geological Survey; AI, aggregation index; PLADJ, percentage of like adjacency; AREA_AM, area-weighted mean patch area; ENN_AM, area-weighted mean Euclidean nearest neighbor distance; RPR, relative patch richness; SHDI, Shannon's diversity index; SHEI, Shannon's evenness index.

$\dagger$ Landscapes assessed using a 300-m riparian zone for each lake. See Leitão et al. (2006) and McGarigal et al. (2012) for landscape metric details and equations. 
management policy, and combating negative anthropogenic influences (i.e., IS propagation). Regarding the accuracy of 2011 NLCD, previous assessments on the 2001 release put Anderson Level I classification at 85\% and Anderson Level II at 79\% correct (Wickham et al. 2010). The 2011 NLCD was designed with 16 land cover classes; however, 15 land cover types were present across the study area lakes. To assess the landscape-water interface ("lake-landscape"), and building from previous research (i.e., Alberti et al. 2007), a 300-m buffer was used to capture the landscape dynamics of each lake's riparian zone.

Land cover composition, urban and forest class configuration, and landscape diversity measures were quantified using the free landscape ecology software FRAGSTATS version 4.2 (McGarigal et al. 2012). The following 10 land cover composition metrics were relevant across all 126 study area lakes: open space developed, low intensity developed, medium intensity developed, deciduous forest, evergreen forest, mixed forest, pasture/hay, cultivated crops, woody wetlands, and emergent herbaceous wetlands. Landscape ecology scientists have developed a plethora of metrics for quantifying landscape patterns and diversity, and their impacts on disturbance regimes (Sun et al. 2007, McGarigal et al. 2012, Turner and Gardner 2015). Based on literature relevance within previous landscape-aquatic ecological research, the following four land cover class configuration metrics were applied to both developed open space and evergreen forest: aggregation index, percentage of like adjacency (PLADJ), area-weighted mean patch area (AREA_AM), and area-weighted mean Euclidean nearest neighbor distance. Aggregation index equals the number of like adjacencies involving the corresponding developed or forest class, divided by the maximum possible number of like adjacencies of that class type. Percentage of like adjacency equals the sum of the number of like adjacencies for developed or forest class type, divided by the total number of cell adjacencies in the landscape, multiplied by 100 (to convert to a percentage). Area-weighted mean patch area (area-weighted mean) equals the sum of all developed or forest class type areas, multiplied by the proportional abundance of the patch (i.e., patch area divided by class area). Area-weighted mean Euclidean nearest neighbor distance (area-weighted mean) is perhaps one of the simplest measures of developed or forest patch isolation, equals the average Euclidean distance of nearest corresponding patch neighbor, and increases without limit. Three landscape diversity measures included in this study were relative patch richness (RPR), Shannon diversity index (SHDI), and Shannon evenness index (SHEI). Relative patch richness is the summation of land cover types present within the landscape boundary, divided by the maximum number of types specified by the user (i.e., 16), multiplied by 100 (to convert to a percentage). The Shannon indices are perhaps the most widely used diversity measures for quantifying landscape pattern diversity, and are based on information theory. The definitions for the class configuration and landscape diversity metrics were adopted from Leitão et al. (2006) and McGarigal et al. (2012).

\section{Statistical analyses}

To accomplish the three objectives of this study, a spatial analysis was constructed to assess the geographic distribution of AISR across the Adirondack Park, and test relationships between lake and landscape characteristics and AISR. This method was accomplished using a four-step process. To meet the requirements for parametric tests, non-normally distributed parameters were transformed when required. The Shapiro-Wilk normality test was used to establish whether transformation was required, and which mathematical function helped to reach a Gaussian frequency. The independent variables used during the forthcoming multiple regression models were standardized using a z-transformation to set all parameters to a mean of 0 and variance of 1 .

First, the level of global spatial autocorrelation for all variables, and a "hot spot" analysis of AISR, were conducted using Getis-Ord General $\mathrm{G}$ and Getis-Ord Gi*, respectively (Getis and Ord 1992). Getis-Ord Gi* is classified as a local index of spatial association (LISA) test. When investigating IS over geographic extents, it is essential to take into account spatial autocorrelation. The first law of geography states that things near in space are more similar (spatially autocorrelated) than things that are farther apart (Tobler 1970). The Getis-Ord non-stationarity assessments were made using ESRI's ArcGIS 10.2 Spatial Analyst Tools (ESRI 2014). For both the global General G and local $\mathrm{Gi}^{*}$ tests, the distance threshold of 
$50 \mathrm{~km}$ was deemed statistically appropriate using the Incremental Spatial Autocorrelation tool in ArcGIS. Spatial autocorrelation index scores differ from each other; however, positive scores denote similar values are spatially clustered and negative scores denote unlike values are spatially distributed (Wong and Lee 2005). Both global and local Getis-Ord statistics provide $z$-scores and $P$-values, indicating whether features are significantly clustered (global) and where those values patterns are located (local). For statistically significant positive $z$-scores, the larger the $z$-score, the greater the clustering of high values (hot spot); for negative $z$-scores, the smaller the $z$-score, the greater the clustering of low values (cold spot; ESRI 2014). Global-level spatial autocorrelation was assessed for AISR and all 31 lake and landscape explanatory variables (Table 2). The Gi* statistics allows each feature's $z$-score to be illustrated, and was used to display geographic "hot spots" and "cold spots" of AISR across the study area lakes.

Second, a two-tailed Spearman's rank $(\rho)$ correlation coefficient test $\left(r_{\mathrm{s}}\right)$ was used to analyze the relative strengths of relationships between AISR and the 31 lake and landscape characteristic variables for the 126 study area lakes $(n=126)$. Spearman's rank correlation coefficient is a common statistic used for assessing collinearity between two variables. This nonparametric correlation coefficient test is appropriate for evaluating numerical collinearity of both continuous and discrete values, including ordinal values (Lehman 2005). Like other correlation coefficient tests (i.e., Pearson's), Spearman's rank coefficient ranges from 1 to -1 , with values closer to 1 indicating stronger bivariate association. A $P$-value accompanies the Spearman's rank correlation coefficient to signify the relationship's statistical significance. The statistical package JMP (version 11; SAS 2013) was used during this step of the research. Twenty-one lake and landscape predictors had statistical significance bivariate correlations with AISR $(P<0.05$; Table 2$)$.

Third, to help fulfill the second objective of this study, a priori global multiple regression models were developed using a multi-model selection framework (Burnham and Anderson 2002, DinizFilho et al. 2008). Since uncertainty remains regarding which parameters would best predict aquatic invasion, this study also evaluates different lake and landscape conditions simultaneously through multiple regression analysis. To reduce the lake and landscape predictors into an independent dataset, metrics that displayed a high degree of collinearity $\left(r_{\mathrm{s}}>0.75\right)$ were eliminated using a bivariate correlation matrix. When statistical redundancy occurred between two predictors, the variable with the best bivariate correlation with AISR, numerical distribution, and literary justification was kept. The remaining 17 lake and landscape variables were combined to create all conceivable ordinary least-squares (OLS) regression models (i.e., 131,071) for predicting AISR. As stated earlier, the dependent variable follows a Poisson distribution so it was $\log _{10}$-transformed to meet its Gaussian distribution assumption and thus improve the accuracy during model selection. This technique calculates the Akaike weight $\left(w_{i}\right)$ of each model; $w_{i}$ is an Akaike information criterion (AIC)-derived index that scores the probability that model $i$ is truly the best predictive model among all possible models (Terribile et al. 2009). The final multiple regression models were then entered into a Poisson multiple regression statistical framework.

Poisson regression was deemed appropriate as it is regarded as a more appropriate method for analyzing compounding rare events, such as lakes having more and more aquatic invaders. Top models were compared and ranked based on their corrected Akaike information criterion $\left(\mathrm{AIC}_{\mathrm{c}}\right)$ and coefficient of determination $\left(R^{2}\right)$. Corrected AIC has been considered a preferred measure of model fit (see Akaike 1978, Fotheringham et al. 2003). Fotheringham et al. (2004) have suggested the lower the $\mathrm{AIC}_{\mathrm{c}}$ value, the closer the model approximates reality; however, a "serious" discrepancy between two models is when $\mathrm{AIC}_{\mathrm{c}}$ values differ by at least three. To evaluate potential multicollinearity issues, the variance inflation factor (VIF) was also calculated. VIF $>10$ indicates definite problems of multicollinearity; VIF $>2.5$ indicates potential areas of concern. Lastly, the ShapiroWilk normality test was used to assess model residual independence and assure randomly distributed errors. Ultimately, five a priori global multiple regression models were chosen for use in the final step of the spatial analysis (Table 3).

Fourth to complete the second and third objectives of this study, GWR (Fotheringham et al. 2003) was used to evaluate non-stationarity of 
Table 2. Global spatial autocorrelations for all study variables using Getis-Ord General G analysis; Spearman's rank $(\rho)$ correlation coefficients between aquatic invasive species richness (AISR) and all independent lake and landscape measures.

\begin{tabular}{|c|c|c|c|c|c|}
\hline Variable & Observed general G & $z$-Score & $P$ & Spearman's $\rho$ & $\overline{\text { Prob. }>|\rho|}$ \\
\hline \multicolumn{6}{|l|}{ Dependent variable } \\
\hline AISR & 0.009 & $2.707^{* * *}$ & 0.007 & & \\
\hline \multicolumn{6}{|l|}{ Lake and landscape variables } \\
\hline Lake area & 0.005 & $-0.777-$ & 0.437 & 0.368 & $<0.001$ \\
\hline Lake perimeter & 0.006 & $-1.581-$ & 0.114 & 0.342 & $<0.001$ \\
\hline Lake perimeter/area ratio & 0.008 & $2.702^{* * *}$ & 0.007 & -0.298 & $<0.001$ \\
\hline Maximum depth & 0.008 & $-0.420-$ & 0.675 & 0.014 & 0.880 \\
\hline Lake surface elevation & 0.008 & $8.671^{* * *}$ & $<0.001$ & -0.433 & $<0.001$ \\
\hline Lake access type & 0.008 & $2.905^{* * *}$ & 0.004 & 0.281 & 0.001 \\
\hline Distance to nearest invaded lake & 0.008 & $0.995-$ & 0.320 & -0.282 & 0.001 \\
\hline $\begin{array}{l}\text { Game fish abundance: yellow perch, } \\
\text { smallmouth bass, rainbow trout }\end{array}$ & 0.008 & $-0.145-$ & 0.885 & 0.375 & $<0.001$ \\
\hline Distance to I-87 exit & 0.009 & $10.846^{* * *}$ & $<0.001$ & -0.268 & 0.002 \\
\hline Distance to nearest populated place & 0.008 & $-0.482-$ & 0.630 & 0.184 & 0.038 \\
\hline \multicolumn{6}{|l|}{ Land cover composition $\dagger$} \\
\hline Developed, open space (DO) & 0.011 & $5.671^{* * *}$ & $<0.001$ & 0.232 & 0.009 \\
\hline Developed, low intensity & 0.011 & $2.686^{* * *}$ & 0.007 & 0.354 & $<0.001$ \\
\hline Developed, medium intensity & 0.009 & $0.839-$ & 0.401 & 0.451 & $<0.001$ \\
\hline Deciduous forest & 0.009 & $4.311^{* * *}$ & $<0.001$ & -0.268 & 0.003 \\
\hline Evergreen forest (EF) & 0.009 & $8.129^{* * *}$ & $<0.001$ & -0.195 & 0.029 \\
\hline Mixed forest & 0.009 & $4.090^{* * *}$ & $<0.001$ & -0.013 & 0.889 \\
\hline Pasture/hay & 0.021 & $3.128^{* * *}$ & 0.002 & 0.223 & 0.012 \\
\hline Cultivated crops & 0.026 & $4.359^{* * *}$ & $<0.001$ & 0.287 & 0.001 \\
\hline Woody wetlands & 0.009 & $1.325-$ & 0.185 & 0.060 & 0.508 \\
\hline Emergent herbaceous wetlands & 0.005 & $-2.145^{* *}$ & 0.032 & 0.168 & 0.060 \\
\hline \multicolumn{6}{|l|}{ Land cover class configuration $\dagger$} \\
\hline AI, DO & 0.008 & $2.938^{* * *}$ & 0.003 & 0.206 & 0.021 \\
\hline $\mathrm{AI}, \mathrm{EF}$ & 0.008 & $3.421^{* * *}$ & $<0.001$ & -0.129 & 0.151 \\
\hline PLADJ, DO & 0.008 & $2.958^{* * *}$ & 0.003 & 0.273 & 0.002 \\
\hline PLADJ, EF & 0.008 & $3.031^{* * *}$ & 0.002 & -0.075 & 0.407 \\
\hline AREA_AM, DO & 0.010 & $3.639^{* * *}$ & $<0.001$ & 0.315 & $<0.001$ \\
\hline AREA_AM, EF & 0.009 & $3.627^{* * *}$ & $<0.001$ & 0.050 & 0.582 \\
\hline ENN_AM, DO & 0.008 & $-0.127-$ & 0.899 & 0.064 & 0.476 \\
\hline ENN_AM, EF & 0.008 & $2.897^{* * *}$ & 0.004 & -0.058 & 0.522 \\
\hline \multicolumn{6}{|l|}{ Landscape diversity $\dagger$} \\
\hline RPR & 0.008 & $-2.753^{* * *}$ & 0.006 & 0.388 & $<0.001$ \\
\hline SHDI & 0.000 & $-1.691^{*}$ & 0.091 & -0.012 & 0.898 \\
\hline SHEI & 0.008 & $2.999 * * *$ & 0.003 & -0.283 & 0.001 \\
\hline
\end{tabular}

Notes: AI, aggregation index; AREA_AM, area-weighted mean patch area; ENN_AM, area-weighted mean Euclidean nearest neighbor distance; PLADJ, percentage of like adjacency; RPR, relative patch richness; SHDI, Shannon's diversity index; SHEI, Shannon evenness index. Symbol designations: - random spatial pattern; ${ }^{*}<10 \%$ chance random pattern; ${ }^{* *}<5 \%$ chance random pattern; ${ }^{* * *}<1 \%$ chance random pattern. Spatial clustering was determined using a threshold distance of $50 \mathrm{~km}$. A Spearman's correlation coefficient in boldface depicts a statistically significant relationship above the $95 \%$ confidence level.

$\dagger$ Landscapes assessed using a 300-m riparian zone for each lake.

local relationships and prioritize lakes at risk to aquatic invasion. Traditional global regression methods (i.e., OLS) should only be used when the assumptions of spatial randomness and location independence can be met. These conditions are usually not met during regional-scale studies of environmental variables (i.e., land cover), because their distributions are not uniformed over space and usually correspond with their underlying foundation (i.e., soil, geology; King et al. 2005, Wagner and Fortin 2005, Dale and Fortin 2014). When these assumptions of spatial data homogeneity are not met, there is a greater likelihood for type I errors (Dormann et al. 2007) 
Table 3. Poisson regression modeling results, standardized coefficients, and individual $P$ values of independent variables significantly related to aquatic invasive species richness (AISR) across 126 lakes within the Adirondack Region of New York for 2013.

\begin{tabular}{|c|c|c|c|c|c|}
\hline \multirow{2}{*}{$\begin{array}{l}\text { Statistical measures and } \\
\text { independent variables }\end{array}$} & \multicolumn{5}{|c|}{ Models } \\
\hline & Model 1 & Model 2 & Model 3 & Model 4 & Model 5 \\
\hline \multicolumn{6}{|l|}{ Statistical measures } \\
\hline $\mathrm{AIC}_{\mathrm{c}}$ & 112.816 & 123.765 & 119.627 & 114.735 & 113.848 \\
\hline Pseudo- $R^{2}$ & 0.665 & 0.567 & 0.537 & 0.658 & 0.649 \\
\hline VIF max value & 1.628 & 1.937 & 1.076 & 1.693 & 1.669 \\
\hline \multicolumn{6}{|l|}{ Independent variables } \\
\hline Poisson regression standardized constant & $0.000^{* * *}$ & $0.000^{* * * *}$ & $0.000^{* * * *}$ & $0.000^{* *}$ & $0.000^{* * *}$ \\
\hline \multicolumn{6}{|l|}{ Lake and landscape } \\
\hline Lake area & $0.495^{* * * *}$ & - & - & $0.516^{* * * *}$ & $0.449^{* * * *}$ \\
\hline Max depth of lake & $-0.300^{* * *}$ & - & - & $-0.244^{* *}$ & $-0.267^{* * *}$ \\
\hline Lake surface elevation & $-0.216^{* * *}$ & $-0.241^{* * * *}$ & - & $-0.238^{* * *}$ & $-0.190^{* *}$ \\
\hline Distance to nearest invaded lake & $-0.407^{* * * *}$ & $-0.259^{* * *}$ & $-0.399^{* * * *}$ & $-0.426^{* * * *}$ & $0.389^{* * * *}$ \\
\hline Distance to nearest highway exit (I-87) & $-0.228^{* * *}$ & - & $-0.305^{* * * *}$ & $-0.265^{* * *}$ & $-0.230^{* * *}$ \\
\hline Distance to nearest populated place & - & - & $0.222^{* *}$ & - & - \\
\hline \multicolumn{6}{|l|}{ Land cover composition $\dagger$} \\
\hline Percent deciduous forest & - & $-0.246^{* *}$ & - & - & - \\
\hline Percent developed, open space & $0.222^{* *}$ & - & - & - & - \\
\hline Percent developed, low intensity & - & $0.205^{* *}$ & - & - & $0.185^{* *}$ \\
\hline Percent evergreen (coniferous) forest & - & $-0.223^{*}$ & - & - & - \\
\hline \multicolumn{6}{|l|}{ Landscape diversity $\dagger$} \\
\hline RPR & - & - & $0.513^{* * * *}$ & - & - \\
\hline SHDI & - & - & - & $0.185^{*}$ & - \\
\hline
\end{tabular}

Notes: $\mathrm{AIC}_{\mathrm{c}}$ corrected Akaike information criterion; VIF, variance inflation factor; RPR, relative patch richness; SHDI, Shannon's diversity index. Land cover-derived variables from the 2011 National Land Cover Database (USGS 2014). Dash, -, indicate no relation observed. Covariate values are Poisson regression standardized coefficients. Independent model variables have been transformed to meet normality.

$\dagger$ Associated variables calculated using a 300-m riparian zone landscape for each lake.

${ }^{*} P<0.10,{ }^{* *} P<0.05,{ }^{* * *} P<0.01,{ }^{* * * *} P<0.001$.

or a shift in regression coefficients (Bini et al. 2009). Geographically weighted regression, a refinement to traditional regression methods, utilizes a distance decay-weighted philosophy that explicitly deals with the spatial non-stationarity of empirical relationships (Fotheringham et al. 2004). Geographically weighted regression uses a spatial drift method by employing a series of locally linear regressions to produce estimates for every sample location through a moving window selecting information from nearby observations (Fotheringham et al. 2003). Thus, GWR models are not suitable for extrapolation beyond the region in which they were established; however, they are locally more appropriate for descriptive and predictive purposes (Foody 2003). Lastly, according to Kupfer and Farris (2007), GWR has the ability to reduce errors caused by spatial autocorrelation during modeling analyses.
To date, most modeling research conducted on aquatic invasion has used global statistical methods (i.e., OLS), which do not allow for understanding how local inferential relationships change over space. Thus, GWR was used herein to determine whether there was significant spatial non-stationarity in the relationships between lake and landscape characteristics and AISR. The five previously established global multiple regressions were recalculated using GWR modeling methodology. Specifically, GWR herein was undertaken using a bi-square spatial weighting with optimization using The Golden Section Search, searching from $10 \%$ to $99 \%$ of neighbors for kernel bandwidth by minimizing the $\mathrm{AIC}_{\mathrm{c}}$. Next, the popular global Moran's I test (Moran 1950) was used to assess the level of spatial autocorrelation of model residuals for each of the five GWR models. Additionally, spatial correlograms were used to evaluate spatial errors associated 
with AISR, estimated AISR, and GWR model residuals. Once non-stationarity was established, and model fitness confirmed, local regression statistics and parameter estimates were mapped. Lastly, the predicted estimates from the five GWR models were summed and used to rank currently non-invaded lakes most at risk to invasion. The GWR models were created using the free and publicly available software Spatial Analysis in Macroecology (version 4), which was designed specifically to address spatial data needs found naturally in macroecological and biodiversity data (Rangel et al. 2010).

\section{RESULTS}

\section{Patterns of lake and landscape characteristics}

Taking all 126 study area lake-landscapes into account, Getis-Ord General G analysis revealed a degree of statistically significant global spatial autocorrelation for 22 of the 31 lake and landscape explanatory characteristics (Table 2). Specifically, 20 of the lake and landscape variables had geographic patterns with less than $1 \%$ chance of occurring randomly. The response variable's (AISR) spatial distribution also had a very low statistical probability of occurring randomly, with a Getis-Ord General G score and z-score of 0.009 and 2.707, respectively. When examining the local distribution of AISR across the 126 lakes of the Adirondack Region of New York, Getis-Ord Gi* statistic displayed four statistically significant hot spots and one cold spot (Fig. 3). The most significant hot spot, at the $1 \%$ level, stretched from Lake Champlain south to Hadlock Pond along the eastern side of the Park on the I-87 corridor, and includes Lake George. At the 5\% level, in the 1932/1980 Winter Olympic region of the Park, an aquatic invasive hot spot focused around Kiwassa Lake and includes Saranac Lake (Lower), Oseetah Lake, Lake Flower, First Pond-Saranac River, and Second Pond - Saranac River. Two marginally significant hot spots, at the $10 \%$ level, are found within the Park: One focused on Great Sacandaga Lake in the south and one at Chateaugay Lake (Upper) in the north. The statistically significant cold spot focused at Jones Pond, in the central part of Franklin County, and stretched from Lake Kushaqua on its northeast end to Hoel Pond on its southwest end. The LISA analysis divulged a conflicting region between compounding aquatic invaders and more pristine water resources within Franklin County. Lastly, based on the hot spot analysis, the I-87 interstate corridor (locally known as the Northway) should continue to be a region of focus for managing AIS.

\section{Correlation coefficient analysis}

Statistically significant bivariate relationships between AISR as the dependent variable and 21 lake and landscape explanatory variables were found using Spearman's rank $(\rho)$ correlation coefficient test. Of the 21 significant predictors of aquatic invasion, nine were grouped into lake and landscape variables, seven were land cover composition measures, three were developed class configuration metrics, and two were landscape diversity measures (Table 2). Human settlements and their activities related to freshwater recreation are the main propagators of IS for the lake-landscapes evaluated. Higher lake surface elevation and an increased forest proportion within the lake-landscape suppress aquatic invaders. The two strongest positive lake and landscape predictors of AISR were abundance of game fish $\left(r_{\mathrm{s}}=0.38, P<0.001\right)$ and lake area $\left(r_{\mathrm{s}}=0.37, P<0.001\right)$, while the two strongest negative were lake surface elevation $\left(r_{\mathrm{s}}=-0.43\right.$, $P<0.001)$ and distance to nearest invaded lake $\left(r_{\mathrm{s}}=-0.28, P=0.001\right)$. The two strongest positive land cover composition measures were percent medium intensity developed $\left(r_{\mathrm{s}}=0.45\right.$, $P<0.001)$ and percent low intensity developed $\left(r_{\mathrm{s}}=0.35, P<0.001\right)$, while the two strongest negative were percent deciduous forest $\left(r_{\mathrm{s}}=-0.27\right.$, $P=0.003)$ and percent evergreen forest $\left(r_{\mathrm{s}}=-0.20\right.$, $\mathrm{P}=0.029$ ). There were no negative class configuration metrics significantly correlated with AISR; however, the two strongest positive associations with aquatic invasion were developed open space of AREA_AM $\left(r_{\mathrm{s}}=0.32, P<0.001\right)$ and PLADJ $\left(r_{\mathrm{s}}=0.27, P=0.002\right)$. There was one positive landscape diversity predictor of AISR, which was RPR $\left(r_{\mathrm{s}}=0.39, P<0.001\right)$. Conversely, SHEI was the only negative landscape diversity predictor of AISR $\left(r_{\mathrm{s}}=-0.28, P=0.001\right)$. The correlation coefficient analysis clearly indicated that aquatic invasion is impacted by both natural and human-dominated lake and landscape conditions across the Adirondack Park. 


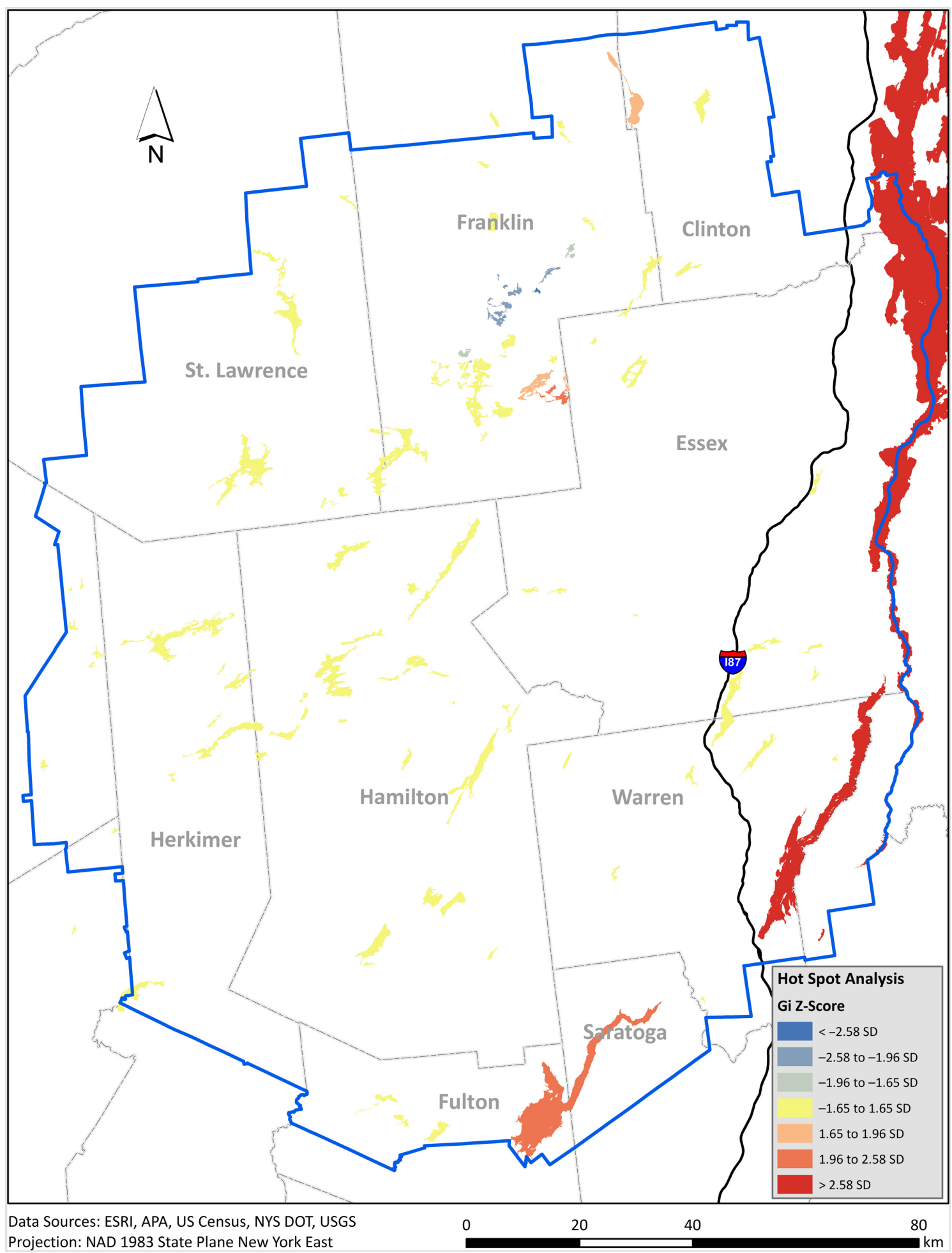

Fig. 3. Hot spot analysis of aquatic invasive species richness across the 126 study area lakes using Getis-Ord $\mathrm{Gi}^{*}$ statistic. The threshold distance parameter was determined within this study and set to $50 \mathrm{~km}$, and spatial weights were standardized by row. 


\section{Global and local multiple regression}

The multi-model selection framework produced five Poisson multiple regression models for predicting AISR across 126 Adirondack lake-landscapes (Table 3). The multi-model exploratory analysis eliminated five of the 17 independent lake and landscape predictors. Twelve explanatory variables were used across the five different global regression models to explain between $54 \%$ and $67 \%$ of AISR variation as expressed by pseudo- $R^{2}$ values. Based on $\mathrm{AIC}_{\mathrm{c}}$ scores, Model $1\left(\mathrm{AIC}_{\mathrm{C}}=112.82\right)$ was the bestfitting model for predicting aquatic invasion, followed by Model $5\left(\mathrm{AIC}_{\mathrm{c}}=113.85\right)$. Variance inflation factor magnitudes ranged between 1.08 and 1.94 for the multiple regression models; thus, errors associated with multicollinearity among covariates were virtually nonexistent. Model 3 used four independent predictors; Model 2 incorporated five independent variables; the other three models incorporated six independent parameters. The Shapiro-Wilk normality test revealed numerical independence of residuals, thus assuring randomly distributed errors for the five regression models. The five distinct models allowed for a separation of independent lake and landscape conditions for understanding their influence on aquatic invaders.

The multiple regression models clearly indicate that the lake and landscape conditions are good predictors of AISR. Based on the multiple regression analysis, distance to the nearest invaded lake should be considered the most important predictor of aquatic invasion. When combined with other independent variables, the distance to the nearest invaded lake was the only constant predictor of AISR across all five models; this covariate had an expected negative association and was significant at the $99 \%$ level for all five models. The distance between the nearest I-87 interstate exit and lake was the second most important parameter for predicting AISR based on four models represented and their covariate significance level. This covariate had a negative association and was significant at the 99\% level for all four models. The third most important predictor of AISR was lake surface elevation, with covariate presence in four models. Across the Adirondacks, lake surface elevation had a negative association with AISR and was significant at the $99 \%$ level for three models and 95\% level for one model. As expected, lake area was found to be an important predictor of AIS. This independent variable was found in three of the five multiple regression models, and recorded the strongest standardized beta coefficient for each. Lake area had a positive association with AISR for all three models at the 99\% significance level. Maximum lake depth was present in three models, had a negative association with AISR, and was significant at the $99 \%$ level for two models and at the 95\% level for one model. The proportion of the lake-landscape occupied by low-intensity developed land cover was the last parameter present in more than one model. This covariate recorded positive association and statistical significance at the $95 \%$ level for two models. The following four parameters were positively associated with AISR and appeared in one model: distance to nearest populated place, percentage developed open space, RPR, and SHDI. The deciduous and coniferous forest percentages of the lake-landscape were both negatively associated with AISR, and appeared in one multiple regression model each.

Geographically weighted regression improved overall model fitness and corroborated inferential relationships established during the preceding global Poisson multiple regression analysis for predicting aquatic invasion across 126 Adirondack lakes. When conducting local regression analyses, it is important to note which independent variables had non-stationarity. Of the 12 explanatory variables previously established for the five different regression models, only lake area, maximum lake depth, and distance to the nearest populated place were spatially random. Nine numerically independent lake and landscape predictors, and the response variable AISR, were spatially dependent (non-stationary) based on the preceding Getis-Ord General G analysis. The five local regressions as modeled by GWR explained between $76 \%$ and $83 \%$ of AISR variation (Table 4). The estimated and observed AISR for 126 Adirondack lakes, estimated using GWR with an adaptive kernel bandwidth selection for minimizing $\mathrm{AIC}_{\mathrm{C}}$ showed a best-case-fitting performance of $83 \%$ (Fig. 4). Based on GWR $\mathrm{AIC}_{\mathrm{c}}$ scores, Model $5\left(\mathrm{AIC}_{\mathrm{C}}=215.00\right)$ was the bestfitting model for predicting aquatic invasion, followed by Model $1\left(\mathrm{AIC}_{\mathrm{c}}=221.56\right)$. Based on the adaptive kernel selection procedure, the number of neighbors included in the GWR models ranged 
Table 4. Geographically weighted regression parameter estimates for multiple regressions between lake and landscape predictors and aquatic invasive species richness (AISR) across 126 lakes within the Adirondack Region of New York for 2013.

\begin{tabular}{|c|c|c|c|c|c|}
\hline Statistical measures and independent variables & Model 1 & Model 2 & Model 3 & Model 4 & Model 5 \\
\hline \multicolumn{6}{|l|}{ Diagnostic statistics } \\
\hline $\mathrm{AIC}_{\mathrm{c}}$ & 221.560 & 241.128 & 271.290 & 222.701 & 214.998 \\
\hline$R^{2}$ & 0.819 & 0.755 & 0.759 & 0.819 & 0.829 \\
\hline Adaptive kernel neighbors & $70.769 \%$ & $91.848 \%$ & $45.718 \%$ & $70.959 \%$ & $70.265 \%$ \\
\hline Sigma & 0.270 & 0.344 & 0.384 & 0.270 & 0.255 \\
\hline Number of parameters & 20.049 & 12.995 & 22.897 & 20.527 & 20.313 \\
\hline$F$ & 25.174 & 29.003 & 14.825 & 24.515 & 26.588 \\
\hline$P$ value & $<0.001$ & $<0.001$ & $<0.001$ & $<0.001$ & $<0.001$ \\
\hline Residuals global Moran's I z-score & $1.020 \%$ & $0.948 \ddagger$ & $-0.270 \ddagger$ & $1.319 \$$ & $0.217 \ddagger$ \\
\hline \multicolumn{6}{|l|}{ Local regression parameter descriptive statistics: (median) } \\
\hline Constant & 0.635 & 0.739 & 0.564 & 0.669 & 0.653 \\
\hline \multicolumn{6}{|l|}{ Lake and landscape } \\
\hline Lake area & 0.441 & - & - & 0.454 & 0.413 \\
\hline Max depth of lake & -0.245 & - & - & -0.245 & -0.223 \\
\hline Lake surface elevation & -0.049 & -0.389 & - & -0.067 & -0.001 \\
\hline Distance to nearest invaded lake & -0.326 & -0.235 & -0.341 & -0.326 & -0.328 \\
\hline Distance to nearest interstate highway exit (I-87) & -0.117 & - & -0.421 & -0.152 & -0.114 \\
\hline Distance to nearest populated place & - & - & 0.159 & - & - \\
\hline \multicolumn{6}{|l|}{ Land cover composition $\dagger$} \\
\hline Deciduous forest & - & -0.261 & - & - & - \\
\hline Developed, open space & 0.107 & - & - & - & - \\
\hline Developed, low intensity & - & 0.185 & - & - & 0.175 \\
\hline Evergreen (coniferous) forest & - & -0.248 & - & - & - \\
\hline \multicolumn{6}{|l|}{ Landscape diversity $\dagger$} \\
\hline RPR & - & - & 0.356 & - & - \\
\hline SHDI & - & - & - & 0.081 & - \\
\hline
\end{tabular}

Notes: $\mathrm{AIC}_{\mathrm{c}}$ corrected Akaike information criterion; RPR, relative patch richness; SHDI, Shannon's diversity index. Land cover-derived variables from the 2011 National Land Cover Database (USGS 2014). Dash, -, indicate no relation observed. Independent model variables have been transformed to meet normality, and standardized to set the mean at 0 and variance to 1 . Spatial autocorrelation of residuals was assessed using the established distance threshold of $50 \mathrm{~km}$.

$\dagger$ Associated variables calculated using a 300-m riparian zone landscape for each lake.

\$ Spatial pattern was not significantly different from a random distribution.

from 58 (45.72\%) for Model 3 to 116 (91.85\%) for Model 2; albeit, Models 1, 4, and 5 all incorporated 89 (70.27-70.96\%) neighbors. The median values of all the local regression coefficients corroborated those directional relationships established between AISR and the lake and landscape explanatory variables during the global Poisson technique. The Moran's I test revealed spatial independence of residuals, thus assuring error randomness for each unique regression model. Overall, there was a $16 \%$ model improvement when using the local regression method compared to the global approach of this study.

A key benefit of using GWR is that variation in model parameters can be mapped out geographically to help elucidate those inferential relationships through local pattern analysis. Using

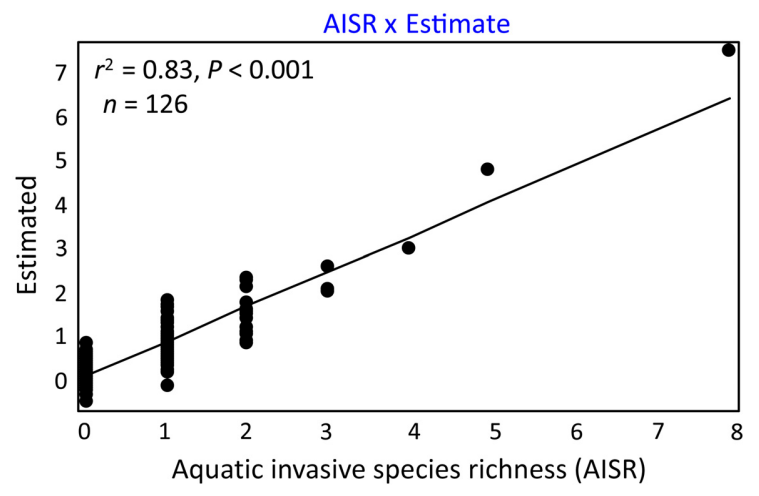

Fig. 4. Observed vs. predicted plot for aquatic invasive species richness as established by Model 5 (Table 4) from the geographically weighted regression analysis. 


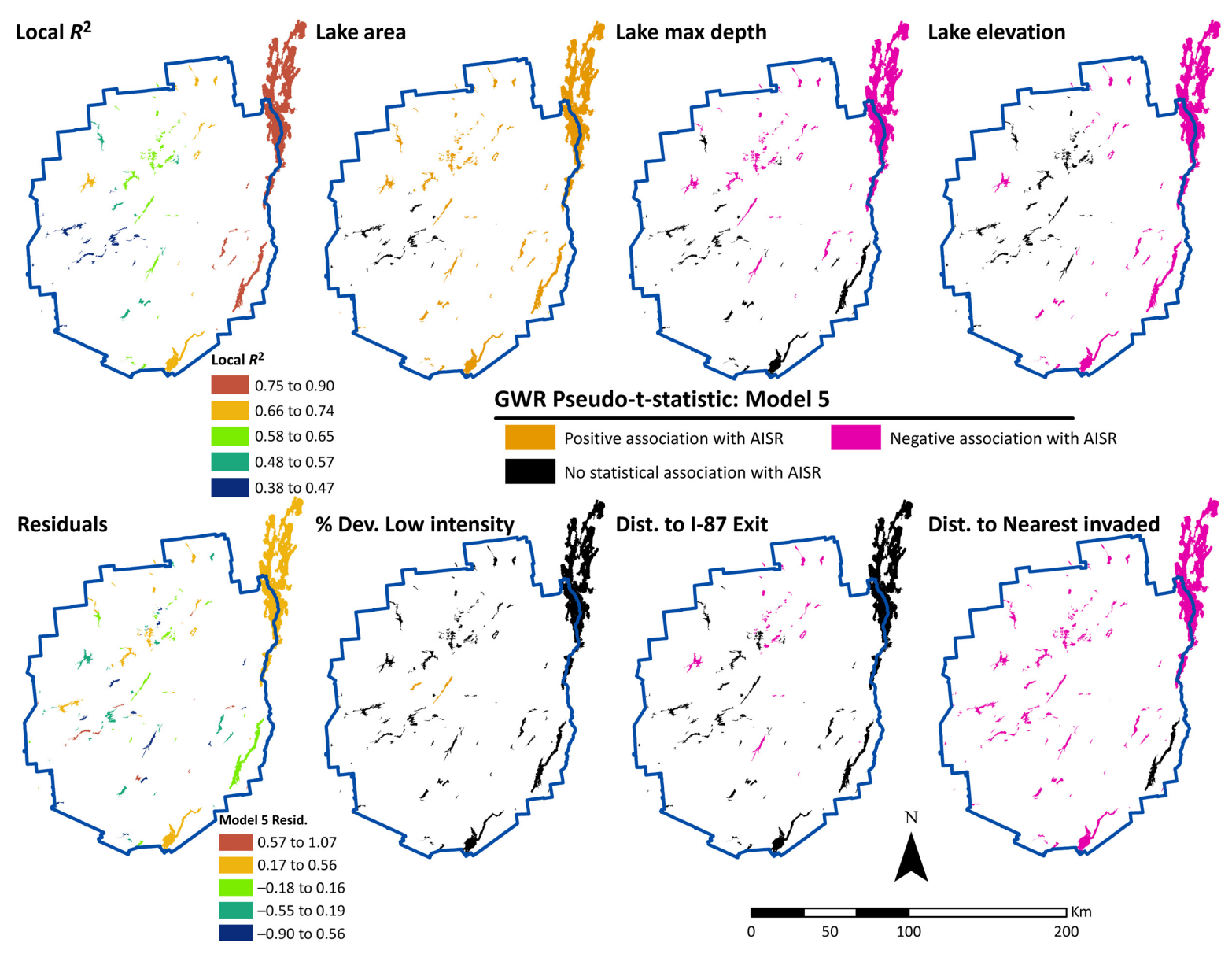

Fig. 5. Local $R^{2}$ and standardized residuals of the geographically weighted regression (GWR) Model 5 (Table 4); spatial distribution of GWR Model 5 local pseudo-t-values $(\alpha=0.05)$ for lake and landscape covariates.

positive and negative 1.96 as the upper and lower thresholds for significant, pseudo-t-statistics was used to plot out where the relationship between lake and landscape characteristics and AISR was significant and positive, significant and negative, and non-significant at the $95 \%$ confidence level. Pseudo-t-statistics was used to present local directionality of local estimated coefficients and their corresponding local statistical significance $(\alpha=0.05)$ for the best-fitting GWR model. Those values, along with local $R^{2}$, and the standardized residuals were mapped for Model 5 from the GWR analysis (Fig. 5). Unlike global modeling methods, the spatial pattern of coefficient of determination $\left(R^{2}\right)$ from the GWR model displayed local variation; furthermore, Model 5 had values ranging from 0.38 in the southwest part of the Park to 0.90 along the eastern extent. The local variation in model fitness supports that GWR has the ability to better capture the spatial nonstationarity associated with explaining aquatic invasion.

Model 5 included two positive and four negative lake and landscape condition parameters for explaining AISR. Based on the spatial distribution of the local covariate lake area, it has the strongest positive influence on AISR. Lake area remains significant to aquatic invasion throughout the Park, other than a zone of insignificance in the southwest. The other positive predictor of AISR was percent low-intensity developed land, but the local association was only found statistically significant at two lakes in the central part of the Park. Based on the estimated local pattern of distance to nearest invaded lake, it had the strongest negative influence on AISR. The distance to 
A.

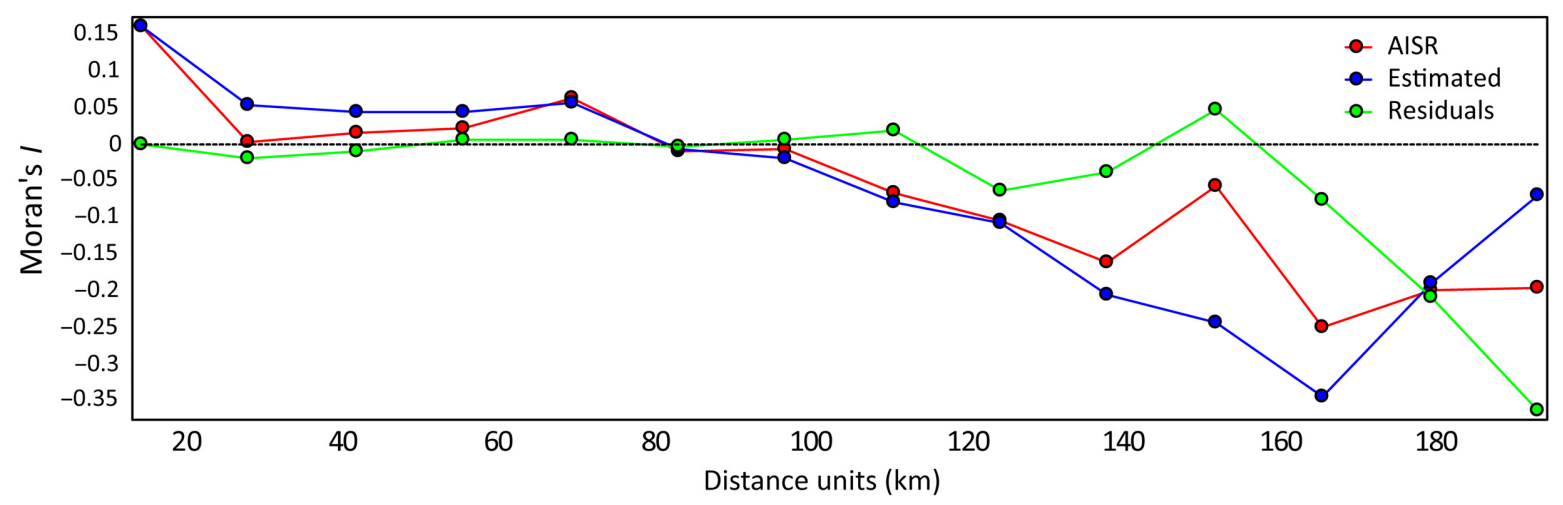

B.

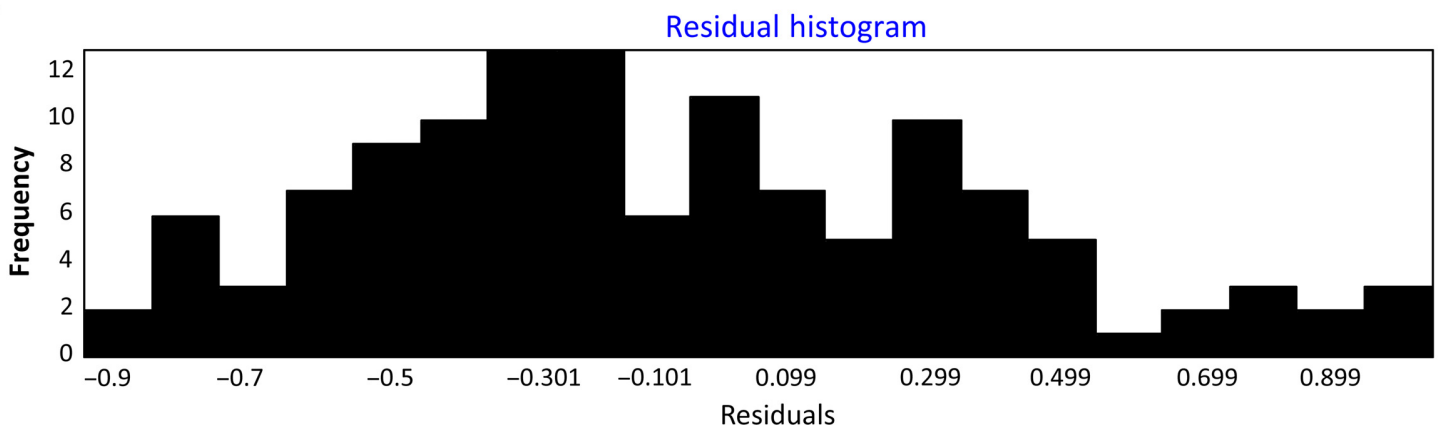

Fig. 6. Spatial correlogram of aquatic invasive species richness (AISR), estimated AISR value, and model residuals for Model 5 (Table 4) from the geographically weighted regression (GWR) analysis (A); and frequency distribution of GWR Model 5 residuals (B).

nearest invaded lake was statistically significant across all Park lakes at the 95\% confidence level, except for Lake George. The local estimate of lake elevation had a statistically significant and negative influence on AISR for much of the eastern half of the Park. Maximum lake depth and distance to the nearest I-87 exit were both negatively associated with AISR, and their local estimates were found statistically significant mostly in the northern part of the Park. The differences in observed vs. predicted AISR were visualized through mapping the standardized residuals in Fig. 5. An ex post facto assessment of Model 5 illustrated the spatial trends of AISR, estimated AISR, and model residuals using Moran's I correlogram (Fig. 6A) and residual histogram (Fig. 6B). Overall, GWR greatly improved the accuracy and information gained for modeling aquatic invasion across Adirondack Park lakes. Due to the modeling improvements from the GWR analysis, this technique was deemed superior for predicting future aquatic invasion. From the five GWR models, the predicted estimates of AISR were summed and used to rank the top 20 non-invaded lakes (Appendix S1: Table S1, Fig. S1). Corroborating the findings from the earlier univariate "hot spot" analysis of AISR, the GWR summed results suggest that Franklin County has the most non-invaded waterways at risk to future aquatic invasion.

\section{DISCUSSION}

\section{Importance of explanatory variables}

Accurately predicting patterns of aquatic invasion requires an understanding of how physical and human-created landscapes alter water resources and thus dispersal, establishment, growth, colonization, and spread of AIS. The lake and landscape characteristics associated with the presence of aquatic invaders in Adirondack water bodies were linked to both natural 
and anthropogenic causes. Across the modeling techniques, the most important natural factor affecting the probability of a lake having more aquatic invaders was lake elevation. The highest elevations in the Park have surficial geology dominated by igneous anorthosite rocks, underlain by metamorphic quartzites and marbles; furthermore, sedimentary rocks (e.g., limestone, shales, sandstones) are exposed sparsely at lowest elevations around the periphery of the Park. As with Nilsson and Haikanson (1992), the low weathering rates of igneous and metamorphic surficial and bedrock are likely not an important determinant of water chemistry. Therefore, it is deduced that the positive correlation between lake elevation and AISR supports the dispersal of aquatic invaders through natural flowage of connected waterways in the Park. Additionally, lake elevation likely captures driving behaviors of recreational boaters, as higher and complex topography decreases available transportation routes and inevitably puts greater strain on automobiles towing small-craft boats.

The positive correlation between lake area and AISR was expected, and the findings of this study follow the species-area relationship found commonplace in ecological literature. That being, larger habitat areas (i.e., larger lakes) are more likely to contain more species, and this relationship has been supported mathematically across numerous ecological studies. Landscape composition of deciduous and evergreen forest impacts the level of dissolved carbon and associated chemistry in lakes. Dissolved carbon, and its impacts on lake alkalinity, has been documented to inhibit invasive milfoil growth (see Buchan and Padilla 2000). As Eurasian Watermilfoil and Variable-leaf Milfoil are two of the most abundant aquatic invaders within Adirondack waterways, the negative relationship between percent forest covers and AISR was expected. Deeper lakes were also negatively correlated with AISR; this relationship suggests that most aquatic invaders of this study are linked to photosynthesis directly or indirectly in the photic zone. Therefore, shallower water bodies have increased littoral zone proportions and thus a higher likelihood of invasive plants and animals. Lastly, the distance to nearest invaded water body had an anticipated consistent and negative explanatory variable of AISR and can be justified by the first law of geography, connected hydrology, and distance decay of traveling boaters.

Lake and landscape conditions associated with greater human population, anthropogenic pressures, and behavior were more dominant predictors of aquatic invasion across the Adirondack Park. From the modeling techniques employed, the most important human-dominated parameter impacting whether a lake will have more aquatic invaders was percent urban land cover. Specifically, increased human abundance-related variables, and their connected modification and metabolization of more natural land covers, increase the likelihood of aquatic invaders. Urbanization measures were consistently found positively correlated with aquatic invasion, and this relationship could be supported by salt and petroleum-based runoff, residential fertilizer use, and mowing disturbances; however, more likely this significant relationship is capturing greater population density and increased recreational lake use. Three of the four urban land cover class configuration metrics were significantly associated with AISR, based on the correlation coefficient analysis; however, none of the forest configuration measures rendered a statistically significant relationship. The urban configuration results reveal that more tightly connected developed lands are associated with higher AISR values. Again, the interpretation is that the configuration metrics are capturing greater population density and increased recreational lake use. The landscape diversity measures revealed that lake-landscapes more mathematically diverse (fragmented away from naturally contiguous) and uniformed (human-made) render a waterway to have a higher probability of aquatic invaders. Landscape pattern analysis remains largely absent from aquatic invasion research, but the results herein suggest they are useful for helping understand causal relationships. Lastly, from the correlation coefficient analysis, the two agricultural land covers cultivated crops and pasture/ hay were both statistically significant and positively associated with AISR. This relationship was expected as soil nutrient-, nitrogen-, and phosphorous-laden runoff increases eutrophication rates that help establish and support adaptable and tolerant aquatic invaders.

Recreational boating has been suggested to be the greatest propagator of AIS (see Puth and Post 
2005, Rothlisberger et al. 2010), and many explanatory variables of this study support this hypothesis. The most consistent and important recreational lake-use predictor across models was the distance between the nearest I-87 exit and a lake. As this Euclidian distance increases, a simple proxy of travel-time and cost (distance decay), less aquatic invaders are found present in Adirondack lakes. Lake access type and abundance of game fish were both positively correlated with AISR, supporting that lakes with a public boat launch and a greater variety of game fish increase its probability of having more aquatic invaders. The explanatory variable, distance to nearest populated place, helps elucidate lake choice by those recreational users. Across modeling techniques, distance to nearest populated place had a positive relationship with AISR. Adding to the impacts of lake access type, the results suggest that recreational lake users prefer waterways further away from populated places. Perhaps this relationship captures Park visitors lodging in campgrounds or other locations outside of urban landscapes. Not accepting spurious correlations, the findings contrast the urban land cover and associated greater population density impacts on increased presence of aquatic invaders. It is believed that these somewhat juxtaposing associations have captured propagule pressure from both long-term Park inhabitants and more transient visitors. Since permanent occupants and visitors likely impact aquatic invasion differently, new research on this topic could improve monitoring efforts, environmental policy-making, and water resources management across the Adirondack Park.

\section{Management and modeling objectives}

Choosing the best modeling method to predict future aquatic invasion is largely contingent on administration goals and financial constraints. The Adirondack Park is a very unique environmental management domicile, and its unique coupled human-environment remains relatively free of IS. Of the over 340 lakes that have been surveyed in 2015, 70\% are still free of AIS. In the Adirondack Park, there is a landscape-level partnership of more than 30 cooperating partners representing environmental, academic, advocacy, municipal, industry, and resident groups, who combined are called the APIPP to safeguard the region from harmful impacts of IS. Adirondack Park Invasive Plant Program has worked to prevent new infestations by implementing innovative spread prevention programs, such as boat launch steward and boat wash programs at strategic water access sites; enriching a regionwide early detection network that uses professionals and volunteers to detect and report new infestations; and managing established populations to mitigate their negative impacts. When infestations are found, rapid response actions are taken with the goal of eliminating the invaders and preventing spread to any new location. While AIS management in the Park focuses on prevention and early detection/rapid response, occasionally there are some AIS that become established. These populations are often managed long term through mechanical means such as hand harvesting and benthic matting, which is very costly and time-consuming.

Effective IS management and policy development requires planning at the regional level, setting near-, mid-, and long-term priorities, albeit using adaptive management and working with limited resources as efficiently as possible. Despite a strong commitment by governmental and non-governmental organizations, it remains financially and logistically impossible to evaluate all lakes within the Adirondack Park annually. This means that aquatic invaders are likely to propagate through waterways bypassed when managers are required to prioritize monitoring resources. Therefore, improving modeling methods that accurately predict which lakes are most susceptible to invasion greatly aids in prioritization and strategic placement of the limited management resources. In example, spread prevention programs (i.e., boat launch stewards, boat wash stations) could be placed at high-risk un-invaded lakes to ensure that watercraft entering remains free of invasives. Conversely, those same prevention resources should be located at invasion "hot spots" to inspect watercraft exiting to prevent dispersal from these source areas. The statistically significant lake and landscape variables of this study do not necessarily imply causative factors on aquatic invasion as a whole or any specific species used to create AISR; however, their associations have been largely supported by the literature and deemed appropriate for accomplishing the goals of this study. 
Building upon past research (i.e., Buchan and Padilla 2000, Capers et al. 2009), this study propels aquatic invasion prediction forward by using GWR. Geographically weighted regression models not only fit AISR variation better than the global models, but also provided local information regarding inferential relationships between lake and landscape characteristics and AISR. That said, Holt and Lo (2008) suggested that traditional GWR has limits; it assumes spatial heterogeneity for all variables, while some natural and humanmade processes test homogeneous (spatially stationary or random). Additionally, traditional GWR was designed for Gaussian-distributed dependent and independent variables, which are often not found in natural, ecological, or coupled human-environmental systems. To address the conventional GWR modeling limitations, Nakaya et al. (2014) developed the GWR4 spatial analysis software to include a semiparametric GWR framework that combines locally varying and globally fixed independent variables. Furthermore, besides the conventional Gaussian models, GWR4 offers the generalized linear modeling framework including geographically weighted Poisson and logistic regression techniques. These new advancements in spatial analysis methods will further improve understanding of inferential relationships related to IS. That said, local regression methods remain case specific because they are contingent on sample size and locations, unique search radius, and locally restricted mathematical expressions (spatial weighting). Thus, GWR findings from this study cannot be transferred wholesale to other geographic locations; however, the methods used and the new variants of GWR should be considered during future modeling and monitoring efforts of invasion.

\section{CONCLUSIONS}

Landscape-aquatic ecosystems are highly interconnected systems requiring knowledge, information, and new methods to manage them appropriately. This paper provides the first macroscale study of aquatic invasion across the Adirondack Park by fulfilling its three guiding objectives. First, aquatic invaders were summed for 126 lakes from the publicly available APIPP (APIPP 2013) report. By doing so, AISR was created as a biotic endpoint of aquatic invasion for spatial analysis across the Adirondack Park. Using Getis-Ord Gi* as a LISA (Getis and Ord 1992), "hot spots" and "cold spots" of AISR were displayed. Second, alternative statistical models were developed and compared to reveal which lake and landscape characteristics were most likely to support aquatic invaders, and to indicate which parameters have the greatest predictive power of AISR. Specifically, Spearman's rank $(\rho)$ correlation coefficient test $\left(r_{\mathrm{s}}\right)$, Poisson regression, and GWR were employed as modeling tools within this research. Although spatial autocorrelation was found and adjusted for, the inferential relationships between lake and landscape characteristics and AISR held true across global and local methods. Third, GWR was used to evaluate non-stationarity of local relationships and to assess its use for prioritizing lakes at risk to invasion. Spatial heterogeneity for six key explanatory variables was illustrated from the best-fitting GWR model. Summation of AISR's predicted estimates from the five GWR models allowed for ranking the top 20 non-invaded lakes at risk to future aquatic invasion, furthermore prioritizing which lakes need to be monitored more frequently.

The results inform that inexpensive and publicly accessible lake and landscape data, typically available from digital repositories within state environmental management agencies, can be used to develop predictions of aquatic invasion with remarkable agreement. Additionally, using freely available spatial analysis software, relatively inexpensive tools with low rates of misclassification for slowing the spread of aquatic invaders were created through an applied example. The lake and landscape characteristics found statistically significant to AISR are generally important to the introduction, establishment, and spread of aquatic invaders. The inferential findings from this study contribute to the scientific, planning, and management literature and can be generalized to similar landscapes of geography, climate, and habitats. While other aquatic invasion studies have investigated statistical associations with lake and landscape parameters, few have attempted to employ the statistical results to predict the spatial variability of significant relationships. Besides the lake and landscapes predictors used in this study, lake-use statistics, measures of hydrogeology, lake chemistry, riparian soils, substrate, native species, 
invader establishment time, habitat, and atmospheric deposition of nitrate, ammonium, and sulfate should be considered when available. Additionally, more research remains for predicting the presence of individual AIS using local logistic regression. River connectivity and drainage patterns (networks) impact dispersal of aquatic invaders and thus need more spatial analysis attention. Where data are available, although a limitation for this study, predictions should be validated using observed cases outside ones used to create the original statistical models.

Overall, the variation in AISR across the Adirondack Park is the result of both natural and human-dominated landscape conditions. The risk posed by aquatic invaders is expressed through the complex interplay among three factors: existence of a hazard, exposure to the hazard, and vulnerability to adverse impacts once exposed. The research presented here demonstrates the capacity for using lake and landscape patterns to effectively characterize risk due to the interaction between hazard existence and exposure. A fertile area for future work will be to examine how vulnerability is inhibited or enhanced by the internal ecological integrity of lakes by incorporating additional data such as aquatic native species richness and other limnological factors for individual lakes. By exploring aquatic invasion patterning across the Adirondacks, and its correlations with common lake and landscape characteristics, aquatic ecological integrity, environmental management, conservation planning, and water resources policy can be strengthened. In conclusion, studies like this one help to improve humanity's relationship with its life-supporting ecosystems.

\section{ACKNOWLEDGMENTS}

We gratefully thank Meghan Johnstone and Brendan Quirion of the Adirondack Park Invasive Plant Program (APIPP) for contributing data and local knowledge to this study. We would also like to recognize Shannon Strelioff, graduate from Ryerson University's Masters of Spatial Analysis program, for assisting with GIS land cover processing. This research was made possible through funding from Binghamton University (SUNY) and Ryerson University to Richard R. Shaker.

\section{Literature Cited}

Akaike, H. 1978. A Bayesian analysis of the minimum AIC procedure. Annals of the Institute of Statistical Mathematics 30(Part A):9-14.

Alberti, M., D. Booth, K. Hill, B. Coburn, C. Avolio, S. Coe, and D. Spirandelli. 2007. The impact of urban patterns on aquatic ecosystems: an empirical analysis in Puget lowland sub-basins. Landscape and Urban Planning 80:345-361.

APA [Adirondack Park Agency]. 2015. Adirondack Parklike Agency 2015 Annual Report. http:// www.apa.ny.gov/Documents/Reports/2015ApaAnn ualReport.pdf

APIPP [Adirondack Park Invasive Plant Program]. 2013. 2013 Annual Report. http://adkinvasives.com/ wp-content/uploads/2014/01/2013-APIPP-AnnualReport.pdf

APSLMP [Adirondack Park State Land Master Plan]. 2014. State of New York. February, 2014. http://www. apa.ny.gov/Documents/Laws_Regs/APSLMP.pdf

Baron, J. S., N. L. Poff, P. L. Angermeier, C. N. Dahm, P. H. Gleick, N. G. Hairston Jr., R. B. Jackson, C. A. Johnston, B. D. Richter, and A. D. Steinman. 2002. Meeting ecological and societal needs for freshwater. Ecological Applications 12(5):1247-1260.

Bini, L. M., et al. 2009. Coefficient shifts in geographical ecology: an empirical evaluation of spatial and non-spatial regression. Ecography 32:193-204.

Buchan, L. A., and D. K. Padilla. 2000. Predicting the likelihood of Eurasian watermilfoil presence in lakes, a macrophyte monitoring tool. Ecological Applications 10:1442-1455.

Burnham, K. P., and D. R. Anderson. 2002. Model selection and multimodel inference: a practical information-theoretic approach. Second edition. Springer-Verlag, New York, New York, USA.

Butchart, S. H., et al. 2010. Global biodiversity: indicators of recent declines. Science 328:1164-1168.

Capers, R. S., R. Selsky, G. J. Bugbee, and J. C. White. 2007. Aquatic plant community invasibility and scale-dependent patterns in native and invasive species richness. Ecology 88:3135-3143.

Capers, R. S., R. Selsky, G. J. Bugbee, and J. C. White. 2009. Species richness of both native and invasive aquatic plants influenced by environmental conditions and human activity. Botany-Botanique 87:306-314.

Connelly, N. A., C. R. O'Neill Jr., B. A. Knuth, and T. L. Brown. 2007. Economic impacts of zebra mussels on drinking water treatment and electric power generation facilities. Environmental Management 40:105-112.

Dale, M. R., and M. J. Fortin. 2014. Spatial analysis: a guide for ecologists. Second edition. Cambridge University Press, Cambridge, UK. 
Diniz-Filho, J. A. F., T. F. L. Rangel, and L. M. Bini. 2008. Model selection and information theory in geographical ecology. Global Ecology and Biogeography 17:479-488.

Dormann, C. F., et al. 2007. Methods to account for spatial autocorrelation in the analysis of species distributional data: a review. Ecography 30:609-628.

Driscoll, C. T., et al. 2001. Acidic deposition in the Northeastern United States: sources and inputs, ecosystem effects, and management strategies. BioScience 51:180-198.

Elton, C. S. 2000. The ecology of invasions by plants and animals. University of Chicago Press, Chicago, Illinois, USA.

EO (Executive Order) 13112. 1999. Invasive species. https://www.gpo.gov/fdsys/pkg/FR-1999-02-08/pdf/ 99-3184.pdf

ESRI [Environmental Systems Research Institute]. 2014. ArcGIS 10.2. Environmental Systems Research Institute, Redlands, California, USA.

Foley, J. A., et al. 2005. Global consequences of land use. Science 309:570-574.

Foody, G. M. 2003. Geographical weighting as a further refinement to regression modelling: an example focused on the NDVI-rainfall relationship. Remote Sensing of Environment 88:283-293.

Fotheringham, A. S., C. Brunsdon, and M. Charlton. 2003. Geographically weighted regression: the analysis of spatially varying relationships. John Wiley \& Sons, West Sussex, UK.

Fotheringham, A. S., C. Brunsdon, and M. Charlton. 2004. Quantitative geography. Sage, London, UK.

Gerland, P., et al. 2014. World population stabilization unlikely this century. Science 346:234-237.

Getis, A., and J. K. Ord. 1992. The analysis of spatial association by use of distance statistics. Geographical Analysis 24:189-206.

Gleick, P. H. 2003. Global freshwater resources: softpath solutions for the 21st century. Science 302:1524-1528.

Grime, J. P. 2006. Plant strategies, vegetation processes, and ecosystem properties. John Wiley \& Sons, West Sussex, UK.

Hellmann, J. J., J. E. Byers, B. G. Bierwagen, and J. S. Dukes. 2008. Five potential consequences of climate change for invasive species. Conservation Biology 22:534-543.

Holt, J. B., and C. P. Lo. 2008. The geography of mortality in the Atlanta metropolitan area. Computers, Environment and Urban Systems 32:149-164.

Karr, J. R. 2006. Seven foundations of biological monitoring and assessment. Biologia Ambientale 20:7-18.

Karr, J. R., and E. W. Chu. 1999. Restoring life in running waters: better biological monitoring. Island Press, Washington, D.C., USA.
Karr, J. R., K. D. Fausch, P. L. Angermeier, P. R. Yant, and I. J. Schlosser. 1986. Assessing biological integrity in running waters: a method and its rationale. Special Publication 5. Illinois Natural History Survey, Champaign, Illinois, USA.

Karr, J. R., and C. O. Yoder. 2004. Biological assessment and criteria improve total maximum daily load decision making. Journal of Environmental Engineering 130:594-604.

King, R. S., M. E. Baker, D. F. Whigham, D. E. Weller, T. E. Jordan, P. F. Kazyak, and M. K. Hurd. 2005. Spatial considerations for linking watershed land cover to ecological indicators in streams. Ecological Applications 15:137-153.

Kupfer, J. A., and C. A. Farris. 2007. Incorporating spatial non-stationarity of regression coefficients into predictive vegetation models. Landscape Ecology 22:837-852.

Lehman, A. 2005. JMP for basic univariate and multivariate statistics: a step-by-step guide. SAS Institute, Cary, North Carolina, USA.

Leitão, A. B., J. Miller, J. Ahern, and K. McGarigal. 2006. Measuring landscapes: a planner's handbook. Island Press, Washington, D.C., USA.

Leung, B., J. M. Bossenbroek, and D. M. Lodge. 2006. Boats, pathways, and aquatic biological invasions: estimating dispersal potential with gravity models. Biological Invasions 8:241-254.

Liu, J., et al. 2007. Complexity of coupled human and natural systems. Science 317:1513-1516.

Lodge, D. M. 1993. Biological invasions: lessons for ecology. Trends in Ecology \& Evolution 8:133137.

Maezo, M. J., H. Fournier, and B. E. Beisner. 2010. Potential and realized interactions between two aquatic invasive species: Eurasian watermilfoil (Myriophyllum spicatum) and rusty crayfish (Orconectes rusticus). Canadian Journal of Fisheries and Aquatic Sciences 67:684-700.

MEA (Millennium Ecosystem Assessment). 2005. Ecosystems and human well-being: synthesis. Island Press, Washington, D.C., USA.

McGarigal, K., S. A. Cushman, and E. Ene. 2012. FRAGSTATS: spatial pattern analysis program for categorical maps. http://www.umass.edu/landeco/ research/fragstats/fragstats

McNeil, B. E., R. E. Martell, and J. M. Read. 2006. GIS and biogeochemical models for examining the legacy of forest disturbance in the Adirondack Park, NY, USA. Ecological Modelling 195:281-295.

Moran, P. A. P. 1950. Notes on continuous stochastic phenomena. Biometrika 37:17-33.

Naiman, R. J., and M. G. Turner. 2000. A future perspective on North America's freshwater ecosystems. Ecological Applications 10:958-970. 
Nakaya, T., M. Charlton, P. Lewis, C. Brunsdon, J. Yao, and S. Fotheringham. 2014. GWR4 user manual. GWR4: window application for geographically weighted regression modelling. https://geodacenter. asu.edu/drupal_files/gwr/GWR4manual.pdf

Nierzwicki-Bauer, S. A., et al. 2010. Acidification in the Adirondacks: defining the biota in trophic levels of 30 chemically diverse acid-impacted lakes. Environmental Science \& Technology 44: 5721-5727.

Nilsson, A., and L. Håkanson. 1992. Relationships between drainage area characteristics and lake water quality. Environmental Geology and Water Sciences 19:75-81.

Novotny, V. 2003. Water quality: diffuse pollution and watershed management. John Wiley \& Sons, West Sussex, UK.

Novotny, V., A. Bartošová, N. O'Reilly, and T. Ehlinger. 2005. Unlocking the relationship of biotic integrity of impaired waters to anthropogenic stresses. Water Research 39:184-198.

Olson, E. R., S. J. Ventura, and J. B. Zedler. 2012. Merging geospatial and field data to predict the distribution and abundance of an exotic macrophyte in a large Wisconsin reservoir. Aquatic Botany 96:31-41.

Pimentel, D., R. Zuniga, and D. Morrison. 2005. Update on the environmental and economic costs associated with alien-invasive species in the United States. Ecological Economics 52:273-288.

Pimentel, D., et al. 2001. Economic and environmental threats of alien plant, animal, and microbe invasions. Agriculture, Ecosystems \& Environment 84:1-20.

Puth, L. M., and D. M. Post. 2005. Studying invasion: Have we missed the boat? Ecology Letters 8: 715-721.

Rahel, F. J., and J. D. Olden. 2008. Assessing the effects of climate change on aquatic invasive species. Conservation Biology 22:521-533.

Rangel, T. F., A. F. Diniz-Filho, and L. M. Bini. 2010. SAM: a comprehensive application for Spatial Analysis in Macroecology. Ecography 33:46-50.

Regalado, S. A., and D. L. Kelting. 2015. Landscape level estimate of lands and waters impacted by road runoff in the Adirondack Park of New York State. Environmental Monitoring and Assessment 187:1-15.

Roley, S. S., and R. M. Newman. 2008. Predicting Eurasian watermilfoil invasions in Minnesota. Lake and Reservoir Management 24:361-369.

Roset, N., G. Grenouillet, D. Goffaux, D. Pont, and P. Kestemont. 2007. A review of existing fish assemblage indicators and methodologies. Fisheries Management and Ecology 14:393-405.
Rothlisberger, J. D., W. L. Chadderton, J. McNulty, and D. M. Lodge. 2010. Aquatic invasive species transport via trailered boats: What is being moved, who is moving it, and what can be done. Fisheries 35:121-132.

SAS Institute. 2013. JMP system for statistics. SAS Institute, Cary, North Carolina, USA.

Shaker, R. R. 2015a. The spatial distribution of development in Europe and its underlying sustainability correlations. Applied Geography 63:304-314.

Shaker, R. R. 2015b. The well-being of nations: an empirical assessment of sustainable urbanization for Europe. International Journal of Sustainable Development \& World Ecology 22:375-387.

Shaker, R. R., and T. J. Ehlinger. 2014. Exploring nonlinear relationships between landscape and aquatic ecological condition in southern Wisconsin: a GWR and ANN approach. International Journal of Applied Geospatial Research 5:1-20.

Shaker, R. R., C. J. Rapp, and A. D. Yakubov. 2013. Examining patterns of aquatic invasion within the Adirondacks: an OLS and GLM approach. Middle States Geographer 46:1-11.

Shaker, R., L. Tofan, M. Bucur, S. Costache, D. Sava, and T. Ehlinger. 2010. Land cover and landscape as predictors of groundwater contamination: A neural-network modelling approach applied to Dobrogea, Romania. Journal of Environmental Protection and Ecology 11:337-348.

Shandas, V., and M. Alberti. 2009. Exploring the role of vegetation fragmentation on aquatic conditions: linking upland with riparian areas in Puget Sound lowland streams. Landscape and Urban Planning 90:66-75.

Sharpe, V. A., B. G. Norton, and S. Donnelley. 2001. Wolves and human communities: biology, politics, and ethics. Island Press, Washington, D.C., USA.

Simberloff, D. 1996. Impacts of introduced species in the United States. Consequences 2:13-22.

Simberloff, D., I. M. Parker, and P. N. Windle. 2005. Introduced species policy, management, and future research needs. Frontiers in Ecology and the Environment 3:12-20.

Sun, H., W. Forsythe, and N. Waters. 2007. Modeling urban land use change and urban sprawl: Calgary, Alberta, Canada. Networks and Spatial Economics 7:353-376.

Terribile, L. C., J. A. F. Diniz-Filho, M. Á. Rodríguez, and T. F. L. Rangel. 2009. Richness patterns, species distributions and the principle of extreme deconstruction. Global Ecology and Biogeography 18:123-136.

Tobler, W. R. 1970. A computer movie simulating urban growth in the Detroit region. Economic Geography 46:230-240. 
Turner, M. G., and R. H. Gardner. 2015. Landscape ecology in theory and practice: pattern and process. Second edition. Springer-Verlag, New York, New York, USA.

USGS (U.S. Geological Survey). 2014. The national map. Earth Resources Observation and Science (EROS) Center. Sioux Falls, San Diego, USA. https://nationalmap.gov/

Vitousek, P. M., C. M. D'Antonio, L. L. Loope, M. Rejmanek, and R. Westbrooks. 1997. Introduced species: a significant component of humancaused global change. New Zealand Journal of Ecology 21(1):1-16.

Vitousek, P. M., C. M. D'Antonio, L. L. Loope, and R. Westbrooks. 1996. Biological invasions as global environmental change. American Scientist 84:468.

Wagner, H. H., and M. J. Fortin. 2005. Spatial analysis of landscapes: concepts and statistics. Ecology 86:1975-1987.

Wickham, J. D., S. V. Stehman, J. A. Fry, J. H. Smith, and C. G. Homer. 2010. Thematic accuracy of the
NLCD 2001 land cover for the conterminous United States. Remote Sensing of Environment 114:1286-1296.

Wilcove, D. S., D. Rothstein, J. Dubow, A. Phillips, and E. Losos. 1998. Quantifying threats to imperiled species in the United States. BioScience 48:607-615.

Wilson, E. O. 2002. The future of life. Vintage Books, New York, New York, USA.

Wong, D., and J. Lee. 2005. Spatial analysis of geographic information with ArcView GIS and ArcGIS. John Wiley \& Sons, West Sussex, UK.

$\mathrm{Wu}, \mathrm{J}$., and R. Hobbs. 2007. Key topics in landscape ecology. Cambridge University Press, Cambridge, UK.

WWF [World Wildlife Fund for Nature International]. 2015. Living Planet Report 2014. UNEP World Conservation Monitoring Center, Geneva, Switzerland. http://wwf.panda.org/about_our_earth/all_ publications/living_planet_report/

Zhang, C., and K. J. Boyle. 2010. The effect of an aquatic invasive species (Eurasian watermilfoil) on lakefront property values. Ecological Economics 70:394-404.

\section{SUPPORTING INFORMATION}

Additional Supporting Information may be found online at: http://onlinelibrary.wiley.com/doi/10.1002/ecs2. $1723 /$ full 